\title{
DOES MEDICAL MALPRACTICE LAW IMPROVE HEALTH CARE QUALITY?
}

\author{
BY Michael FRAKES, CORNELL UNIVERSITY*
}

\author{
Anupam B. Jena, HaRvard Medical SCHOol, Massachusetts General Hospital, and NBER
}

Despite the fundamental role of deterrence in justifying a system of medical malpractice law, surprisingly little evidence has been put forth to date bearing on the relationship between medical liability forces on the one hand and medical errors and health care quality on the other. In this paper, we estimate this relationship using clinically validated measures of health care treatment quality constructed using data from the 1979 to 2005 National Hospital Discharge Surveys and the 1987 to 2008 Behavioral Risk Factor Surveillance System records. Drawing upon traditional, remedy-centric tort reforms-e.g., damage caps-we estimate that the current liability system plays at most a modest role in inducing higher levels of health care quality. We contend that this limited independent role for medical liability may be a reflection upon the structural nature of the present system of liability rules, which largely hold physicians to standards determined according to industry customs. We find evidence suggesting, however, that physician practices may respond more significantly upon a substantive alteration of this system altogether-i.e., upon a change in the clinical standards to which physicians are held in the first instance. The literature to date has largely failed to appreciate the substantive nature of liability rules and may thus be drawing limited inferences based solely on our experiences to date with damage-caps and related reforms.

JEL Classification: I18, K13

Keywords: malpractice; health care quality; deterrence; defensive medicine

\footnotetext{
* Cornell Law School, 314 Myron Taylor Hall, Ithaca, NY 14853 (email: mdf96@cornell.edu). We are grateful to Amy Finkelstein and Jon Gruber for their guidance and advice. We are likewise grateful for helpful comments received from Ronen Avraham, Bernie Black, David Hyman, Louis Kaplow, Justin McCrary, Michelle Mello, Mark Ramseyer, Max Schazenbach, Steve Shavell, Charlie Silver, Holger Spamann, Brad Wendel, Kathy Zeiler and seminar participants at the Harvard Law, Economics \& Organization Seminar, the Northwestern Law and Economics Colloquium, the Midwestern Law and Economics Association Annual Meeting, the University of Texas Medical Malpractice Roundtable and the Cornell Law School Faculty Retreat. We are also thankful to Negasi Beyene, Maria Owings and the staff at the Research Data Center at the National Center for Health Statistics for their help with the National Hospital Discharge Survey files and to Ronen Avraham for providing data on state tort laws. Frakes acknowledges support from the National Institute on Aging, Grant Number T32-AG00186 and Jena acknowledges support from the Office of the Director, National Institutes of Health (NIH Early Independence Award, 1DP5OD017897-01)
} 


\section{INTRODUCTION}

Among the key rationales typically invoked to support the medical malpractice liability system is the notion that medical liability forces can incentivize physicians to improve the quality of care that they provide to patients. Somewhat surprisingly, however, little direct evidence exists on whether malpractice law actually provides such a "deterrent" effect to physicians. Rather, the empirical malpractice literature has somewhat deemphasized considerations of medical quality and medical errors and has paid significantly more attention to the relationship between malpractice pressure and measures of treatment utilization and health care costs, i.e. “defensive medicine.” Although studies of defensive medicine generally demonstrate that greater health care spending or utilization, prompted by greater malpractice pressure, is infrequently associated with significant improvements in broad measures of mortality, it is nearly universally recognized that such mortality measures themselves are poor surrogates for more direct measures of health care treatment quality. It is therefore essentially unknown whether the tort system is achieving one of its stated goals: to improve the quality of care provided by physicians through deterrent forces. Answering this question is the focus of this paper.

We approach this question using direct, clinically validated measures of health care treatment quality rather than aggregate mortality, which is more reflective of social, environmental, and personal health risk factors than of treatment quality itself. In particular, using data from the National Hospital Discharge Surveys from 1979 to 2005 and the Behavioral Risk Factor Surveillance System from 1987 to 2008, we analyze the effect of medical malpractice liability on several comprehensive inpatient and outpatient health care quality metrics including: (1) risk-adjusted inpatient mortality rates for selected medical conditions (e.g., 
acute myocardial infarctions, hip fractures and strokes), which have been argued to specifically reflect the quality of inpatient care, (2) avoidable hospitalization rates and cancer screening rates, which reflect the quality of outpatient care provided by physicians, and (3) adverse-event rates to mothers during childbirth, which reflect an alternative, patient-safety-focused indicator of inpatient quality.

Collectively, these indicators account for four of the five domains of quality targeted by the OECD's Health Care Quality Indicator's project and for each of the three domains of quality promulgated by the Agency for Health Care Research and Quality (AHRQ). We note, of course, that particular quality measures may induce greater liability fears among physicians than others, given the frequency with which lawsuits arise in the associated medical contexts. For instance, cancer screening rates may be especially good measures to study the link between malpractice and health care quality given that missed cancer diagnoses constitute a frequent basis for malpractice lawsuits (Schiff et al. 2013).

We employ two approaches to identifying the influence of liability forces on health care quality. First, we take the more traditional route in the literature which typically estimates difference-in-difference specifications that draw upon the adoption of caps on non-economic damages awards and related reforms (i.e., ‘traditional reforms' or “damage cap reforms”). These plausibly exogenous reforms primarily serve to decrease the expected consequences of liability and by doing so allow us to evaluate the impact on health care quality of malpractice reforms that essentially maintain the basic structure of the tort system, but that simply blunt its severity. Second, in contrast to these traditional, remedy-focused reforms, we study the impact on quality of care of more substantive reforms which directly alter the standards of care against which physicians are judged in medical malpractice suits. In particular, we study changes in state-level 
laws which led to the retreat from rules which expected physicians to follow customary local practices and the contemporaneous adoption of rules that physicians be held to national standards of care (Frakes 2013).

The empirical malpractice literature to date, which again has focused primarily on damage-cap reforms, has largely viewed medical liability forces in a rather abstract sense. It has spoken about liability "pressure," without necessarily asking: "pressure to do what?” We demonstrate that this failure to appreciate the substantive nature of liability rules and the clinical expectations such rules place on physicians may leave analysts relying solely upon our experiences to date with traditional reforms with incomplete information regarding the potential role of medical liability in shaping physician practices. We contend that, even if observed levels of health care quality happen to be relatively insensitive to the adoption of a damage cap or related remedy-focused reform, one would be premature to take such findings to conclude that physicians are, in fact, universally unresponsive to liability forces. Relative to such traditional reforms, substantive reforms that change the standards against which physicians are judged hold the potential to more directly and powerfully influence physician practice patterns. Such latter reforms thus merit separate attention.

To understand the intuition behind the insufficiency in merely relying upon the results of the damage-cap studies, one must first understand the substantive nature of our present liability rules. In determining the legal standards against which physicians should be judged, malpractice law generally defers to customary market practices. In other words, physicians determine their own standards. Liability forces in a system of this nature thus impose few independent expectations on physicians. Generally, physicians in such a system may only alter their practices in response to liability fears due to uncertainty in their beliefs as to how courts will assess 
customary practices-i.e., they may aim to deliver higher quality than otherwise customarily desired over fear that courts will misjudge customary practices to entail such higher practices. Damage caps may therefore only induce changes in physician practices to the extent that they reduce the cost of uncertainty to physicians about whether their practice patterns deviate negatively from customary market practices. Caps otherwise do not alter the clinical expectations being placed upon physicians.

One might not be surprised to find that the channel of influence inherent in a customfocused liability system is limited in its ability to independently induce substantially higher levels of care. After all, as just suggested, liability forces in this system may only incentivize higher levels of care as a result of blind guesswork on the part of physicians. Consider, in contrast, an alteration of the structure of this system altogether-for example, by changing the way in which the clinical standards expected of physicians are determined in the first place. To the extent that these standards change in a way so as to explicitly expect higher levels of quality, one might be less surprised to find a substantial response in physician behavior. Following a reform of this nature, physicians will not deliver higher quality of care simply because they are guessing that this might be expected of them at court. Rather, they may deliver higher quality care as a result of explicit directions under the law to do so. The potential channel of influence created by standard-of-care reforms are direct and immediate and do not operate through any second-order reduction in uncertainty.

Generally consistent with expectations, our empirical analysis of the impact of remedycentric traditional reforms on the quality of care provided by physicians generally casts doubt upon the independent deterrent effect of medical liability forces in the present custom-focused liability system. For each measure of health care treatment quality, the estimated effect of 
malpractice pressure within our current liability system, as identified by the adoption of noneconomic damage caps and related tort reforms, is both statistically insignificant and small in magnitude, with a 95\% confidence interval that is relatively tightly bound around zero. For instance, at one end of this interval, the lack of a non-economic damages cap - which is indicative of higher malpractice pressure - is associated with only a 2 percent decrease in inpatient mortality rates for selected medical conditions.

Importantly, however, while this remedy-centric-reform analysis implies at most a modest degree of deterrence stemming from the present system of liability rules, the results from the standard-of-care-reform analysis suggests that a substantive alteration of the malpractice system may lead to more meaningful changes in observed measures of quality. For example, for each measure of health care treatment quality, we find that when states modify their standard-ofcare rules to expect physicians to provide a higher level of quality, observed levels of quality increase substantially in the direction of such new expectations. Moreover, when states modify their rules so as to condone lower provision of quality by physicians, physicians do not appear to respond by delivering lower quality care. Changing the legal standard of what is expected of physicians therefore has the potential to improve the quality of care provided by low-quality physicians without reducing the quality of care provided by already high-quality physicians. Our analysis suggests that medical liability forces—under the right structural framework-hold the potential to elevate the quality floor.

The paper proceeds as follows. In Section II, we discuss existing evidence on the deterrent impact of medical liability. Section III presents a simple model of physician decisionmaking and discusses the various sources of ambiguity that cloud the channel of deterrence intended to be created by the malpractice system. Section IV discusses the data and empirical 
methodology. Section V presents the results of the empirical deterrence analysis. Finally, Section VI concludes.

\section{Malpractice LaW ANd Physician Behavior: BaCkgRound}

Relatively limited evidence exists on the degree to which medical malpractice deters undesirable practices and improves health care quality. ${ }^{1}$ Among those studies that do explore this link, most evaluate aggregate health outcome measures such as overall mortality, which by itself poorly reflects the quality of the various clinical processes of care that physicians use to improve health. Moreover, the results of these studies paint a mixed picture. For example, Lakdawalla and Seabury (2009) find that higher county-level malpractice pressure leads to a modest decline in county-level mortality rates., whereas other studies of the impact of malpractice reforms on infant mortality rates generally find no relationship (Klick and Stratmann 2007). Similarly, Frakes (2012), Currie and MacLeod (2008), and Dubay, Kaestner, and Waidmann (1999) each estimate the impact of malpractice pressure on infant Apgar scores (recognized as valid predictors of neonatal health outcomes), ${ }^{2}$ generally finding no evidence consistent with any such relationship. ${ }^{3}$

A major limitation of the above approaches to measuring health care quality is that such broad, outcome-based measures are likely to be driven by many factors other than the quality of care actually delivered at particular outpatient and inpatient encounters (McClellan and Staiger 1999). These factors include differences in access to health care across regions as well as

\footnotetext{
${ }^{1}$ Whatever has been done has largely been conducted rather tangentially in connection with investigations into the physician supply-related impacts of malpractice law or into the relationship between malpractice forces and health care costs and treatment utilization rates. For a general review of the more direct evidence bearing on deterrence (up to 2002), see Mello and Brennan (2002).

${ }^{2}$ See, for example, Casey et al. (2001).

${ }^{3}$ Various other studies similarly calculate health outcome measures based on mortality rates that are focused on more targeted populations. For instance, Kessler and McClellan (1996) estimate a trivial relationship between liability reforms and (1) survival rates during the one year period following treatment for a serious cardiac event (e.g., acute myocardial infarction), and (2) hospital readmission rates for repeated serious cardiac events over that period. Sloan and Shadle (2009) undertake a similar analysis.
} 
variations in a range of other factors that the public health literature has identified as being meaningful determinants of health status - e.g., socioeconomic status, individual risky behaviors, living conditions, social support networks, etc. Although Apgar scores and infant mortality rates are arguably more connected to a particular encounter - i.e., the delivery itself - delivery outcomes are also significantly influenced by environmental, physical and medical factors throughout the full term of the pregnancy and not simply the delivery. While outcomes such as general mortality rates and infant mortality rates are unquestionably important, the possibility of a multitude of determinants of one's health status raises statistical concerns over the ability to reliably identify the link between variations in the malpractice environment and the indicated health outcomes.

A key advantage of focusing the malpractice inquiry on those measures emphasized by the medical literature is that the promoted measures are, by their very design, better reflective of the influence of the delivered health care itself. Moreover, while some of the indicators continue to emphasize mortality-related outcomes, other indicators, such as avoidable hospitalizations, adherence to cancer screening guidelines, and maternal traumas, bear on a broader range of morbidity- and non-mortality-related impacts. Very few malpractice studies have investigated the link between malpractice law and the type of quality metrics emphasized by the medical community. In one recent study, Greenberg et al. (2010) document a positive association between adverse events incurred during hospitalizations (measured according to the Agency of Health Care Research and Quality's (AHRQ) Patient Safety Indicators) and subsequent claiming of malpractice. However, rather than exploring the way in which liability pressure may lead ex ante to improved patient safety - i.e., deterrence - they instead focus on studying how 
improvements in patient safety (perhaps arising from a range of initiatives) alleviate ex post liability exposure for providers.

One study that perhaps most directly explores the impact of liability pressure on a relevant set of quality metrics is Currie and MacLeod (2008). The authors find that damage cap adoptions increase preventable complications of labor and delivery, suggesting that higher liability pressure improves patient safety. Iizuka (2013) likewise finds that certain tort reformse.g., collateral source rule reforms and punitive damage caps-increase labor and deliveryrelated complications (using the ob-gyn-specific patient safety indicators promulgated by the AHRQ). Interestingly, Iizuka finds no such relationship with non-economic damage-cap adoptions, despite the fact that non-economic damages caps arguably amount to the most significant reduction in liability pressure out of the four traditional reforms that he explores (Paik et al, 2013). Finally, another recent study by Zabinski and Black (2012) explore the impact of Texas' non-economic damage cap adoption in 2003 on a much broader range of patient safety indicators than that considered by Currie and MacLeod (2008) and Iizuka (2013), similarly documenting an increase in the incidence of adverse events upon the lightening of malpractice pressure associated with the damage-cap adoption. With only one treatment group, however, the point estimates from this analysis should be interpreted with caution.

Our analysis builds upon these studies in several important ways. First, as with the Zabinski and Black (2012) study, we explore a broad range of both inpatient and outpatient measures of health care quality that goes beyond the obstetrics context. ${ }^{4}$ While obstetrics has formed the canonical example of research in empirical malpractice, obstetricians themselves

\footnotetext{
${ }^{4}$ Zabinski and Black (2012) explore the impact of Texas' non-economic damage cap adoption in 2003 on a much broader range of patient safety indicators, similarly documenting an increase in the incidence of adverse events upon the lightening of malpractice pressure associated with the damage-cap adoption. With only one treatment group, however, the point estimates from this analysis are likely to be inconsistent (Conley and Taber 2011).
} 
account for less than 3 percent of U.S. physicians. The health care quality processes that we study form the 'bread-and-butter' practices of generalist physicians which form the largest group of practicing physicians. Second, we analyze the quality of health care provided in outpatient settings, a setting which accounts for over $20 \%$ of the nation's total health care dollars (CMS 2011) and has received no special attention by the malpractice deterrence literature. Third, as described below, our analysis also captures a richer degree of variation in relevant tort laws than that considered by both Currie and MacLeod (2008) and Iizuki (2013), resulting in arguably more reliable estimates. Finally, as an alternative and arguably more robust way to investigate the link between liability and quality, we also consider the impact of more structural liability reforms that alter the clinical standards expected of physicians.

\section{MODEL OF PHYSICIAN BEHAVIOR UNDER MALPRACTICE}

\section{A. The effect of traditional malpractice reforms}

This section develops an illustrative model of how physician behavior is affected by malpractice liability and both traditional vs. substantive malpractice reforms. Consider a physician faced with the decision of whether or not to undertake a quality-improving action / precaution, $A$, that comes at a cost of $C$ to the physician. The patients a physician treats are each characterized by a unique disease severity $s$, where higher levels of $s$ reflect greater disease complexity and whereby $s$ follows a uniform distribution across the population. For a patient with disease severity $s$ who receives action A by the physician, the benefit to the patient is $B(s)$, where the benefit is increasing in $s$.

Physicians decide upon a cutoff point, $s$, along the distribution of patient disease complexity at which they begin to take precaution $A$. For patients with disease complexity below this cutoff-i.e., for the healthiest subset of patients - the physician might deem $A$ unnecessary 
given its cost. For risk factor levels above the cutoff point, they will elect to perform the action. Given the uniform distribution of risk factors, this behavior can be summarized by a quality improvement rate of $1-s^{\prime}$.

Now, first assume that the physician's desired cutoff point is influenced solely by their clinical beliefs regarding the appropriateness of $A$ given $s$. She will avoid the quality-improving action as long as its cost, $C$, exceeds the benefits, $B(s)$, of taking the precaution. With levels of $s$ beyond this point, the benefits will surpass such costs and she will undertake the quality improving treatment. An equilibrium will be reached whereby the physician will set her cutoff point at the intersection of the benefit and cost curves. As demonstrated by Figure 1, we signify this particular cutoff at $\hat{s}$.

Of course, other factors could also influence this cutoff decision. For instance, physicians may be compensated more for taking precaution $A$ (i.e., paid “fee-for-service”), which may shift upwards their perceived benefits curve, leading to a lower cutoff point and an associated higher level of precaution-taking. On the other hand, as a result of limitations in their knowledge bases, the benefits that physicians perceive to follow from taking precaution $A$ may fall short of the true benefits. As demonstrated by Figure 2, the benefits that a physician attaches to $A$ may actually follow $B^{*}(s)$. Operating under such beliefs, physicians will set a cutoff point at $s^{*}$, which is higher than the fully-informed (i.e., optimal) point, $\hat{s}$. In this equilibrium in which physicians are imperfectly informed, physicians may not provide treatment $A$ to a subset of patients—i.e., those with $s$ between $\hat{s}$ and $s^{*}$ - for whom the true benefits of treatment exceed the costs.

Continuing with the assumptions in Figure 2, next consider the marginal effect of malpractice liability. First assume that the liability system is free of uncertainty and error-we 
relax this assumption later. The law consistently sets a particular standard of care that the physician is expected to follow and the physician is assumed to be able to determine with certainty what this standard is. Assume further that this standard of care is initially set according to local customs. Because the standard of care is based on customary practices and because physicians are assumed to underestimate the benefit of treatment (i.e., the perceived benefit is $B^{*}(s)$ ), the standard expected under the law will be set at $s^{*}$, the cutoff point (with an associated treatment rate of $1-s^{*}$ ) actually implemented by physicians as a result of their non-liability influences. If a physician fails to provide the quality-improving action $A$ to patients with disease complexities beyond cutoff s*, she may subject herself to liability. If a physician fails to provide treatment in situations where treatment is normally not provided (i.e. $s<s^{*}$ ), even if the true benefits of the precaution surpass its cost in such instances, she will nonetheless avoid liability due to the customary standard for liability.

In this simple case, liability pressure only reinforces the pre-liability equilibrium of treatment provision $\left(\mathrm{s}^{*}\right)$ and incentivizes physicians to continue setting their practices such that they follow a sub-optimal precaution rate of $1-s^{*}$ and a cutoff of $s^{*}$. Thus, as a first-order matter, liability forces under a customary standard of care do not push clinical behaviors in any particular direction. Consequently, in the presence of customary standards of care, diminishing the force of the liability system through the adoption of reforms that render the consequences of malpractice liability less severe-e.g., a damage cap—should not cause physicians to deviate from their customary practice positions.

Now allow for uncertainty to enter the liability determination process. Courts may misperceive what the customary norms of practice actually are. For instance, consider a patient with a disease complexity level just below $s^{*}$, in which case physicians would typically opt not 
to perform $A$ on someone of this health status. If courts have imperfect information about what practice patterns are customary, they may make the incorrect assessment that physicians customarily perform $A$ in such circumstances and thus attribute negligence to this physician. The threat to physicians of malpractice may cause them to reevaluate their customary positions and expand their level of precaution-taking to patients healthier than $s^{*}$. This will be true if the expected damages from liability surpass the physician's perceived net costs of providing treatment $A$ to this patient-i.e., $C-B^{*}(s)$. At some point, however, as $s$ falls below $\mathrm{s}^{*}$, the probability of a negligence determination may become remote enough that the perceived net costs of taking the quality-improving action on such healthy patients outweighs any foregone liability costs and patient health benefits that could come from providing this action. Accordingly, physician uncertainty about the risk of malpractice liability may lead to an increase in treatment levels, though it will unlikely lead to a universal adoption of the treatment. Online Appendix A specifies in greater detail those conditions under which imperfect information among courts about customary standards of care may lead physicians to increase levels of treatment.

To the extent that physicians underestimate the benefits of treatment $A$, the imposition of a liability system which imperfectly measures customary standards of care may therefore compel physicians to increase rates of precaution-taking in the direction of the optimum, $\hat{s}$. In other words, the liability system may induce some amount of welfare-improving deterrence and thus improve observed measures of health care quality on the margin. Similarly, the adoption of reforms that reduce the expected cost to physicians of losing a malpractice suit-e.g., a damage cap—-may undo these liability-related benefits and lead to declines in quality. The extent of any such second-order increase in precaution-taking stemming from the possibility of court error is 
theoretically ambiguous and thus so is the expected decline in quality to be observed from damage-cap adoptions. We test for the existence and degree of such responsiveness in our empirical analysis below.

\section{B. The effect of substantive malpractice reforms}

Interestingly, liability-induced improvements in quality in the above framework may simply stem from imperfect information in courts about the customary practice patterns of physicians, as opposed to stemming from well-delineated legal standards that establish the optimal level of health care quality. In an environment in which a physician's liability is determined solely based on a physician's accordance to customary practices, the independent and marginal effect of liability in deterring medical errors and improving health care quality arises perhaps from happenstance (i.e., imperfect information in courts). This raises the obvious question of whether improvements in quality could arise more cleanly and directly by altering how physician behavior is evaluated by courts in the first place-e.g., by a retreat from using actual customary practices of physicians to determine standards, which may themselves be inherently sub-par, and by the imposition of standards that are based on better-informed science and that directly expect that physicians follow optimal clinical approaches. We stress that this inquiry is more than a mere hypothetical exercise. Many of the proposed "next generation" malpractice reforms under discussion by analysts and policymakers are of this nature-e.g., those in which liability standards are to be set according to compliance with clinical practice guidelines.

To explore this question within our model, consider again a baseline similar to that depicted in Figure 2, whereby physicians reach an equilibrium marked by an insufficient level of treatment and an associated cutoff point at $s^{*}$. Consider now an alternative standard of care 
imposed by courts whereby the law expects that physicians begin providing the qualityimproving action / precaution at $\hat{s}$-i.e., at the efficient point where the true benefits of the precaution begin to surpass its costs. Will this induce physicians to increase their rate of precaution taking? Consider patients with disease complexity in the range between $s^{*}$ and $\hat{s}$. In this range, physicians' own perceptions of the benefits of precaution A fall short of their costs. Should they fail to undertake A, however, they will now be liable under the new standard and will be expected to compensate patients for the forgone benefits that they would have received with treatment, $B(s)$. If physicians provide treatment, given their perceived costs and benefits of treatment, they lose an amount equal to the difference between $\mathrm{C}$ and $B^{*}(s)$. However, if they do not provide treatment, they lose an even greater amount in damages $B(s)$ to the patient. ${ }^{5}$ This induces them to provide treatment to the set of patients with complexities between $s^{*}$ and $\hat{s}$.

It is worth noting that physician behavior may also move in the direction of this new standard for reasons other than liability fears, e.g., through informational forces. By assumption, physicians may have initially provided sub-standard quality due to their failure to fully appreciate the benefits of undertaking the relevant precaution. By retreating from a liability system based on custom that only reinforced those informational deficiencies and by instead imposing a new liability system that sets liability standards optimally, physicians may update their priors regarding the benefits of precaution taking, given the saliency of information that may flow through liability channels. Such updating alone may cause an increase in delivered quality.

In the empirical analysis below, we test whether physicians respond to changes in liability standards that expect a higher (lower) standard of care by delivering higher (lower) levels of quality.

\footnotetext{
${ }^{5}$ By assumption, $B(s)$ is greater than $C$ in this range between $s^{*}$ and $\hat{s}$ and thus is greater than $C-B^{*}(s)$.
} 


\section{DATA AND Methodology}

\section{A. Overview}

We study the impact of malpractice reforms on the quality of health care provided by physicians, as measured by clinically validated quality metrics rather than aggregate outcomes such as overall mortality. We use two data sources which provide information on metrics that reflect the quality of both inpatient and outpatient medical care. First, we collect data on several measures of health care quality (described below) from the 1979 to 2005 National Hospital Discharge Surveys (NHDS), each of which provides a nationally-representative sample of inpatient discharge records from short-stay, non-federal hospitals. Using the relevant diagnosis codes provided by the NHDS, we calculate, for each state and year, mean levels of various inpatient and outpatient health care quality metrics. Second, we use data from the 1987 to 2008 Behavioral Risk Factor Surveillance System (BRFSS) to compute mean state-year averages of various cancer screening rates, a measure of outpatient quality of care. ${ }^{6}$ We then take two approaches in evaluating the impact of malpractice law on health care quality: (1) estimating the association between our observable quality metrics and the adoptions of traditional, remedycentric tort reforms (primarily, non-economic damage caps) and (2) exploring the relationship between health care quality and substantive liability reforms to the manner in which courts determine medical liability standards.

\section{B. Damage Cap Analysis}

The first part of our deterrence analysis explores the general relationship between health care quality and malpractice pressure, as identified by the imposition of traditional tort reforms

\footnotetext{
${ }^{6}$ Not all screening measures are available over this entire time period, however. While longer time periods are available for some measures-e.g., mammograms-others are only available over the 2000s-e.g., PSA testing.
} 
which diminish the severity of punishment rather than modify the benchmark standard of care against which physicians are compared in malpractice litigation. The immediate effect of these tort reforms is largely to reduce the expected levels of damages imposed in the event of liability, without necessarily altering the substantive nature of the liability-determination process. Reducing the expected damages awards, in turn, may leave plaintiffs and/or their attorneys less inclined to bring suit, thereby lessening the level of pressure placed upon physicians. Though generally fully insured against financial risks, physicians may welcome such reduced likelihoods of suit to the extent that they face non-pecuniary or non-insurable costs of liability-e.g., psychological or reputational harms (Jena et al. 2011). The reforms that we emphasize in this analysis, and that have received the most attention by the literature, are caps on non-economic damage awards—i.e., pain and suffering awards.

Non-economic damages represent a significant portion of the typical malpractice award. For example, using a dataset of 326 closed claims in Texas from 1988-2004 (each with at least a $\$ 25,000$ payout), Hyman et al. (2009) document an average non-economic damages award of $\$ 681,000$, compared with $\$ 542,000$ for economic damages. Non-economic damage caps also represent the tort-reform measure that has been most commonly associated with an observed change in certain malpractice outcomes: claims severity, physician supply and malpractice premiums. ${ }^{7}$ Importantly, with respect to the frequency of claims-i.e., the likelihood of suitthe documented effect of caps has varied significantly across studies (Mello and Kachalia 2011). This uncertainty in the literature arguably motivates exploring substantive liability reformse.g., standard-of-care reforms—as an alternative way to explore the relationship between liability and quality. Lending support, however, to the validity of the damage-cap approach to identifying the malpractice / health-care quality link, a recent study by Paik et al. (2013) draws

\footnotetext{
${ }^{7}$ See Mello and Kachalia (2011) for a comprehensive review of relevant studies.
} 
upon significant variation in state laws to find a roughly 29 percent drop in claims frequency upon a damage-cap adoption.

Nearly thirty states currently have non-economic damage cap provisions in place, most of which were adopted during the malpractice crisis of the $1980^{\prime}{ }^{8}{ }^{8}$ In light of the timing of this variation, those studies relying on post-1980s data to evaluate the impact of non-economic damage caps (e.g., Currie and MacLeod 2008) fail to draw on the most relevant sources of variation in malpractice law and consequently rely on few treatment groups. Limited variation of this nature implicates concerns over the reliability of the estimated standard errors and over the consistency of the point estimates - that is, with few treatment groups, it is less likely that spurious correlations between the outcome variable and the reforms of interest will average to zero (Conley and Taber 2011). The NHDS data, supplemented with geographic identifier codes, provides inpatient discharge records from a broad enough span of states and covering a long enough period of time to allow for a deterrence analysis that draws on an extensive set of legislative variations.

Table 1 lists those states that modified their non-economic damage cap laws over the NHDS sample period. In most specifications, we also explore the association between observed health care quality and certain additional types of tort reforms, including reforms of the collateral source rule, caps on punitive-damages awards and other "indirect" tort reforms. Further descriptions of such reforms are provided in Online Appendix B.

\footnotetext{
${ }^{8}$ Following Frakes (2012), we also classify states as having non-economic damages provisions if they have laws that place caps on total damages awards. Such laws, after all, necessarily cap non-economic damages as well. In light of the imposition of state fixed effects, this classification only has relevance in the context of 1 state (Texas) that adopted a total damages cap at a time when it did not have a specific non-economic damage cap in place. Only 1 additional state - i.e., Colorado - adopted a total damages cap over the sample period (2 years following the adoption of a non-economic damages cap). With this in mind, we do not separately control for the incidence of a cap on total damages. However, we estimate nearly identical results for the remaining coefficients when we do include this additional covariate and treat total and non-economic damage caps separately.
} 
Ultimately, by rolling back the influence of the liability system through a reduction in pressure, without altering its substance, such reforms provide us with a mechanism to explore the marginal influence of the present structure of liability standards.

\section{Liability-Standards Analysis}

Unlike reforms focused on curbing remedies available to plaintiffs in malpractice suits, states have done significantly less experimentation along the more substantive and structural dimension to malpractice law-i.e., the standards against which physician behavior is judged. One significant exception, however, is the broad-based shift largely beginning in the 1960s away from the so-called "locality rule."

In the first half of the Twentieth Century, nearly every state had in place malpractice laws which judged physicians in malpractice cases against customary practices of physicians working in the same locality. These laws essentially expected that physicians follow the practices applied by those around them. Deviations in care from these customary standards that led to adverse medical events were judged as negligent. Between the 1960s and the 1990s, however, the majority of states amended their substantive malpractice laws to abandon such locality rules in favor of rules requiring physicians to follow national standards of care, thereby harmonizing the legal expectations of medical care provided by physicians across states. In light of the rampant regional disparities in care that have persisted across regions for decades (see, for example, Wennberg and Cooper 1999), one can view the move from a local to a national-standard rule as a meaningful and substantial alteration of the standards clinically expected of physicians (Frakes 2013).

Variation over time in state adoptions of the national-standard rule offer an alternative approach to exploring the relationship between malpractice law and health care quality, 
specifically allowing us to examine whether the modification of malpractice standards expected of physicians results in a corresponding change in observed quality measures. In terms of the model presented in Section III, if we conceptualize $s^{*}$ as representing the customary practices of a particular locality initially operating under a locality rule and $\hat{s}$ as representing the average customary practices of the rest of the nation, then the abdication of the locality rule may allow us to test for the hypothesized shift from a legally expected cutoff of $\mathrm{s}^{*}$ to $\hat{s}$ in the precaution-taking and quality-improving decision of physicians.

In related work, Frakes (2013) tests the hypothesis that, upon the adoption of a nationalstandard rule for malpractice, physician practices in the affected regions converge towards practices of the rest of the nation, focusing on utilization rates of various obstetric and cardiac treatments and diagnostic procedures. We follow Frakes (2013) and test for the impact of national-standard adoptions by estimating whether mean quality measures in a state that uses a local-standard rule converge towards the relevant national means when the state amends its malpractice laws to require that physicians comply with national standards of care. Table 2 provides more details on the evolution of malpractice-standard rules. Roughly 14 states abandoned the use of local standards in favor of national standards in the post-1978 period, along with 1 additional state (Maryland) that retreated from a previous national-standard adoption. Sixteen states currently retain some element of locality in their standard-of-care laws.

Importantly, this analysis affords us the opportunity to separately test how physicians respond to changes in malpractice standards which in some instances expect higher levels of quality and in other instances lower levels. For each of the quality metrics that we study, a number of treatment states began the sample period with high quality levels while a number of others began with low quality levels, in which event the move towards a national standard 
represented a change in legal expectations in both directions depending on the pre-reform level of quality. In light of the possibility that physicians may respond differently to an elevation of what is expected of them relative to a slackening of what is expected of them, we test for asymmetrical responses to the adoption of national-standard rules. ${ }^{9}$

\section{Quality measures}

The acknowledgement that health care providers are falling short on quality has propelled initiatives designed to fill this gap (e.g., hospital report cards), along with the associated development of quality indicators used to implement such initiatives. Foremost among those organizations developing quality indicators is perhaps the Agency for Healthcare Research and Quality (AHRQ), an agency within the Department of Health and Human Services. AHRQ measures are particularly useful for the present study in so far as they are designed for use with administrative inpatient databases such as the NHDS. Accordingly, for the purposes of this study, we first and foremost look to the AHRQ for guidance in selecting quality metrics to explore. More specifically, inspired by the AHRQ's three domains of quality—i.e., Prevention Quality Indicators (PQIs), Inpatient Quality Indicators (IQIs), and Patient Safety Indicators (PSIs), respectively—we calculate three composite quality metrics: (1) inpatient mortality rates for selected medical conditions, (2) avoidable hospitalization rates and (3) the incidence of maternal trauma during deliveries.

In building off of Currie and MacLeod's (2008) investigation into the quality impacts of liability forces, we likewise consider the quality measure employed in their obstetrics-focused analysis and supplement our PSI-inspired maternal trauma indicator with an indicator capturing

\footnotetext{
${ }^{9}$ As discussed in Section IV below, data limitations force us to focus this liability-standards analysis (at least in our primary tables in the text) on all measures other than the cancer screening measures. Nonetheless, we do provide some limited analysis of this variety for the cancer-screening measures in the Online Appendix.
} 
the incidence of an avoidable complication during the delivery of a child. Finally, we build various quality indicators around cancer-screening practices of physicians, drawing upon another widely embraced quality domain emphasized by the medical community.

We provide a brief overview of each metric below, with additional details regarding the construction of the resulting quality metrics provided in Online Appendix B.

Inpatient mortality for selected conditions. Following the AHRQ's IQIs, we first construct a composite inpatient mortality rate for selected acute medical conditions using data from the National Hospital Discharge Surveys. Unlike overall mortality rates computed over the entire jurisdiction affected by a relevant legal regime, IQI-inspired mortality rates are designed to capture mortality events likely associated with a clinical encounter itself and the associated quality of care during that encounter, rather than unobserved socioeconomic characteristics that affect overall mortality within a population. To rule out selection concerns-i.e., concerns regarding the liability regime impacting the probability of patients appearing in the inpatient environment in the first place-this measure focuses on mortality among a subsample of discharges in which the primary diagnosis code indicates select medical conditions (e.g., acute myocardial infarction, stroke, etc.) that uniformly entail hospitalization upon their occurrence. We further risk adjust this composite rate for fluctuations in the incidence of the various conditions comprising the sub-sample. ${ }^{10}$ Such risk adjustment addresses concerns that an increase in the proportional incidence of one of the lesser-mortality conditions within the sample

\footnotetext{
${ }^{10}$ In alternative specifications (not shown), we estimate the relationship between liability reforms and the rate of hospitalization for each such condition (e.g., hip fractures), where this rate is calculated relative to the total number of hospitalizations within this subsample of selected conditions. The results suggest very little relationship, if any, between liability pressure and the distribution of conditions comprising this subsample. For instance, at the upper end of the 95 confidence interval, the adoption of a non-economic damages cap is associated with only a 0.7 percent increase in the relative rate of hip fracture admissions among this subsample.
} 
(e.g., hip fractures) could lead to a reduction in the observed mortality rate with no actual improvement in quality.

Avoidable hospitalizations as a measure of outpatient quality. The second quality measure that we employ captures the rate of avoidable hospitalizations (AH) within each stateyear cell, a measure that is inspired by the AHRQ's PQIs. Though constructed using inpatient data, AH rates are widely argued by physicians to reflect the quality of care prevailing in the associated outpatient community. Such measures identify conditions (e.g., hospitalization for asthma exacerbation, uncontrolled diabetes, and uncontrolled hypertension, etc.) with respect to which proper outpatient care would have prevented the need for hospitalization.

Our baseline specifications implicitly assume that malpractice liability may only impact $\mathrm{AH}$ rates through the influence of liability pressure on the quality of care delivered to outpatients. However, in theory, physicians may hold some degree of discretion over the decision to admit patients who present to the hospital with the indicated conditions. Liability may influence this hospitalization decision in various ways. For instance, fearful over liability for failing to hospitalize a patient, physicians may admit those marginal patients whom they may have otherwise decided did not warrant hospitalization. A response of this nature could confound the analysis by masking the presence of a true deterrent effect at the outpatient level. Of course, liability fears could also impact the hospitalization decision in the opposite direction if liability fears induce hospitals and providers to avoid high risk patients (Mello et al. 2005) or to avoid hospitalizations out of concern that hospitalization itself could lead to malpractice liability if an unexpected adverse event occurred. In any event, to address such concerns, in alternative specifications, we construct an $\mathrm{AH}$ rate that focuses only on a subset of avoidable hospitalizations with little physician discretion over the decision to hospitalize-i.e., focusing on 
hospitalizations that both could be prevented through quality outpatient care and whose incidence are generally insensitive to the discretion of admitting physicians at hospitals (e.g., ruptured appendix).

Maternal Trauma and Complications. Patient-safety indicators (PSIs) capture complications and adverse events that take place in inpatient settings following surgeries, procedures and deliveries. We focus our analysis of PSIs on those related to delivery / childbirth for two reasons. First, as previously addressed, prior empirical malpractice literature has focused heavily on assessing the impact of malpractice pressure on obstetrical outcomes. Second, many PSIs reflect the quality of care provided during surgeries, rates of which may be a function of the liability environment (e.g., rates of surgery may in theory be more or less common in environments with high malpractice pressure, creating issues of selection). Rates of childbirth, on the other hand, are unlikely to be impacted by malpractice pressures.

We create estimates of obstetric PSIs using data from the National Hospital Discharge Surveys. For the sake of simplicity and to maximize the sample size for this analysis, we group together cesarean trauma events with vaginal delivery trauma events (with and without instruments) and thus construct a composite obstetric trauma indicator (though the analysis does not change substantially when considering each separately). To look at a broader, but related set of obstetric-related complications, we follow Currie and MacLeod (2008) and also consider the incidence of preventable delivery complications-e.g., fetal distress, excessive bleeding, precipitous labor, prolonged labor, dysfunctional labor, etc.

Cancer Screening as a measure of outpatient quality. To complete our measurement of the quality of outpatient care, we use patient self-reports from the Behavioral Risk Factor Surveillance System from 1987 to 2008 to compute state-year incidences of mammography, 
physical breast exam, Prostate-Specific Antigen (PSA) testing, digital rectal exam, pap smear, and sigmoidoscopy / colonoscopy, used to screen for breast, prostate, cervical, and colon cancer, respectively. As explained in greater detail in Online Appendix B, we use national cancer screening guidelines to select the relevant age groups for the analysis and the window period of relevance for the exam-e.g., mammography within the previous two years for females and sigmoidscopy / colonscopy starting at age 50 and at least once every 5 years). In Online Appendix C, we discuss the robustness of the above results to alternative formulations of cancer screening rates.

Descriptive statistics. On average, each NHDS state-year cell contains roughly 424 discharges associated with the selected conditions used in the composite inpatient mortality rate measure, our first quality indicator. The average inpatient mortality rate among this sub-sample is 8 percent, as presented in Table 3. Likewise, each state-year cell contains an average of roughly 1017 avoidable hospitalizations. As explained in Online Appendix B, we form AH rates by normalizing $\mathrm{AH}$ counts by an index of hospitalizations for low-discretionary medical conditions-e.g., acute myocardial infarction, stroke, etc.-in which case this denominator captures the size of the relevant state-year cell without itself being sensitive to legal or financial incentives. With this normalization, the average AH rate across state-year cells equals 1.7. Furthermore, each state-year cell in the NHDS contains on average roughly 600 deliveries. Within this delivery subsample, maternal trauma (third or fourth degree lacerations) occurs nearly 4 percent of the time and preventable complications occur nearly 16 percent of the time. Finally, cancer screening rates among the relevant BRFSS participants ranges, on average, from 40 to 73 percent. 
To describe the variation in quality of care across regions, Column 2 of Table 3 provides, for each quality indicator, a measure of the average gap over the sample period between the mean state level and the associated mean national level. More specifically, following Frakes (2013), we summarize this gap by calculating the mean absolute deviation between the state and national indicator levels (for each year) and normalizing this rate by the national level. For instance, on average over the sample period, the mean maternal trauma rate within a state differed from the national mean trauma rate by an amount equal to roughly 26 percent of the national level. Because this measure is computed over the entire sample period, this measure to some degree understates the regional disparity measure that is most relevant to our analysis. In particular, in early years of the sample and among states which began the sample under a locality-rule regime, the average gap between the state and the national rate, for each of the listed indicators, is substantially larger than the figures provided in Table 3. In the empirical analysis below, we explore whether these gaps are narrowed through the adoption of national-standard rules (approaching the inquiry separately from each side of the regional quality distribution).

\section{E. Specifications}

We estimate the effect of traditional medical malpractice reforms—e.g., damage-capson the quality of care provided by physicians through the following specification:

$$
\log \left(Q_{s, t}\right)=\alpha+\boldsymbol{\gamma}_{\mathbf{s}}+\boldsymbol{\lambda}_{\mathbf{t}}+\boldsymbol{\varphi}_{\mathbf{s}} t+\beta_{1} C A P_{s, t}+\boldsymbol{\beta}_{\mathbf{2}} \mathbf{X}_{\mathbf{s}, \mathbf{t}}+\boldsymbol{\beta}_{\mathbf{3}} \mathbf{Z}_{\mathbf{s} \mathbf{t}}+\boldsymbol{\beta}_{\mathbf{4}} \mathbf{0}_{\mathbf{s}, \mathbf{t}}+\varepsilon_{s, t}
$$

where $s$ indexes state and $t$ indexes year. $C A P_{s, t}$ represents an indicator variable for the presence of a cap on non-economic damages in state $s$ and year $t$. State fixed effects, $\gamma_{\mathrm{s}}$, and year fixed effects, $\lambda_{t}$, control for fixed differences across states and across years, respectively. $Q_{s, t}$ represents the relevant healthcare quality measure - e.g., the composite inpatient mortality rate or 
the avoidable hospitalization rate. The coefficient of interest in each specification is captured by $\beta_{1}$, representing the relationship between the relevant quality measure and the adoption of noneconomic damage caps.

To control for a range of additional state-year factors, $\mathbf{X}_{\mathbf{s}, \mathbf{t}}$ represents certain demographic characteristics (e.g., percentage of patients in various age, sex, race and insurance categories), along with certain mean characteristics of the represented hospitals (e.g., bed size and ownership types). $\mathbf{Z}_{\mathbf{s}, \mathrm{t}}$ represents certain other state-year characteristics (HMO penetration rate, physician concentration rate, and median household income). $\mathbf{O}_{\mathbf{s}, \mathrm{t}}$ is a matrix representing a set of indicator variables for the incidence of collateral source rule reforms, caps on punitive damages, and "indirect” tort provisions. In some specifications, we include state-specific linear time trends, $\varphi_{\mathrm{s}} \mathrm{t}$, to control for slowly-moving correlations between the relevant quality measures in a state and the adoption of tort reforms by that state. ${ }^{11}$ For each of the relevant quality indicators, Online Appendix B provides additional details regarding the compositions of $\mathbf{X}$ and $\mathbf{Z}$.

For the obstetrics-focused and cancer-screening measures, we estimate a specification identical to that indicated above except at the individual-year level (as opposed to the state-year level), using, as appropriate, the full sample of deliveries in the NHDS records (for the obstetrics measures) or the full sample of individual respondents (of the specified age bands) within the BRFSS. The dependent variables in these analogous individual specifications represent the individual incidence of either (1) a traumatic event to the mother-i.e., a PSI event, (2) a

\footnotetext{
${ }^{11}$ Frakes (2013) documents a relationship between the adoption of laws requiring physicians to follow national (as opposed to local) standards and a resulting convergence in physician practices across regions. In light of the fact that two of the damage-cap treatment states used in the defensive-medicine analysis below (Hawaii and Texas) were dropped from the specifications estimated in Frakes (2013) (due to an inability to classify the full history of their standard-of-care laws), we exclude controls for national-standard laws in the damage-cap specifications estimated below and focus instead on the traditional tort reform measures. However, the results presented below are robust to the inclusion of controls for national-standard laws (not shown).
} 
preventable delivery complication or (3) the receipt within the relevant time period of the respective cancer screening measure, depending on the specification. ${ }^{12}$

To explore whether the quality of health care provided by physicians is affected by the clinical malpractice standards expected of physicians under the law, we next explore whether state mean rates for the relevant quality measures converge towards their respective national mean rates as states adopt national-standard rules. In this investigation, however, we allow for a differential convergent response from the top and the bottom of the regional quality distribution - that is, we allow for a different response when the law changes so as to expect a higher level of quality of physicians compared to when the law changes so as to condone a lower level of quality. Following Frakes (2013), we estimate the following specification:

$$
\begin{gathered}
\log \left(Q_{s, t}\right)=\alpha+\boldsymbol{\gamma}_{\mathbf{s}}+\boldsymbol{\lambda}_{\mathbf{t}}+\boldsymbol{\varphi}_{\mathbf{s}, \mathbf{t}}+\boldsymbol{\beta}_{\mathbf{1}} \mathbf{X}_{\mathbf{s}, \mathbf{t}}+\boldsymbol{\beta}_{\mathbf{2}} \mathbf{Z}_{\mathbf{s}, \mathbf{t}}+\boldsymbol{\beta}_{\mathbf{3}} \mathbf{0}_{\mathbf{s}, \mathbf{t}}+ \\
\beta_{4} B E L O W_{s}+\beta_{5} N S_{s, t}+\beta_{6} B E L O W_{s} * N S_{s, t}+\varepsilon_{s, t}
\end{gathered}
$$

where $\mathbf{X}_{\mathbf{s}, \mathbf{t}}, \mathbf{Z}_{\mathbf{s}, \mathbf{t}}, \mathbf{O}_{\mathbf{s}, \mathbf{t}}, \boldsymbol{\gamma}_{\mathbf{s}}, \boldsymbol{\lambda}_{\mathbf{t}}$ and $\boldsymbol{\varphi}_{\mathbf{s}, \mathbf{t}}$ are defined as above. $N S_{s, t}$ represents an indicator for a national-standard law. BELOW is an indicator for a state that began the sample period with an initial rate below the national mean for the relevant quality indicator. The coefficient of $\beta_{5}$ in this interaction specification can effectively be interpreted as the association between nationalstandard laws and quality indicator levels for states with initially above-average indicator levels (i.e., when $B E L O W=0$ ). Note that for all indicators other than cancer screening rates, higher indicator levels represent lower levels of quality (and vice versa); therefore, states with $B E L O W$ $=1$ are those with initially low indicator levels (e.g. mortality) but actually higher than average

\footnotetext{
${ }^{12}$ Similarly, this alternative specification includes $\mathbf{X}_{\mathbf{i}, \mathbf{s}, \mathbf{t}}$ as the individual-specification counterpart to $\mathbf{X}_{\mathbf{s}, \mathbf{t}}$.
} 
quality. For states with initially below-average indicator levels $(B E L O W=1)$, this same association is captured by the sum of $\beta_{5}$ and $\beta_{6}$.

\section{RESUlTS}

\section{A. Damage-Cap Analysis}

Overview

Tables $4-8$ present estimation results from specifications that explore the relationship between non-economic damage caps (and related reforms) and health care quality. For each quality measure, we estimate an association between a non-economic damage-cap adoption and the relevant indicator that is statistically indistinguishable from zero, though relatively tightly bound around zero. ${ }^{13}$ As such, while we cannot rule out that greater malpractice pressure within our existing system—as identified through the lack of a non-economic damages cap-induces higher quality health care, we can rule out that such forces induce substantially higher levels of quality. Similarly, we can rule out that damage cap adoptions which reduce malpractice pressure are associated with substantial reductions in health care quality (note that below we conceptualize our findings both in terms of whether greater liability pressures improve quality and whether diminished pressures weaken quality).

\section{AHRQ-Inspired Measures and Preventable Delivery Complications}

We begin by describing the results for the AHRQ-inspired health care quality indicators and the preventable delivery complications measure (Tables $4-7$ ), considering that these measures all reflect lower levels of quality as the relevant indicator level rises (and vice versa), whereas the cancer screening measures, which we discuss in subsection A(2) below (and Table

\footnotetext{
${ }^{13}$ Reported standard errors in Table $4-8$ and in all subsequent tables are clustered at the state level to allow for arbitrary within-state correlations of the error structure.
} 
8), reflect higher levels of quality as the screening levels rise. We separate the discussions with this difference in mind to ease confusion in exploring the relevant associations.

Upon the adoption of a non-economic damage cap, we estimate mean changes in the inpatient mortality rate for selected conditions, the AH rate, the low discretionary $\mathrm{AH}$ rate, the maternal trauma rate and the preventable delivery complication rate of only $0.8,0.3,-0.5,-2.2$, and -1.2 percent, respectively. ${ }^{14}$ This pattern of point estimates does not change meaningfully upon the inclusion of state-year covariates, other tort laws and state-specific linear time trends, as demonstrated by Columns 2 and 3 in each of Tables $4-7$ and by Columns 6 and 7 of Table 5 ($3.8,-1.0,-1.7,-0.0$, and 4.2 percent, respectively).

These estimates are not significant at the $\mathrm{p}=0.05$ level of significance. Accordingly, we cannot rule out that positive associations between damage caps and these various quality indicators exist - that is, we cannot rule out some decline in quality associated with reductions in liability pressure and thus some improvement in quality associated with increases in pressure. However, even at the upper end of the 95 percent confidence interval, we find that the adoption of non-economic damage caps is associated with only a 6.6, 4.9, 4.3, 5.7, and 6.9 percent increase in those same quality measures, respectively, as indicated near the bottom of each of Tables $4-7$. That is, higher malpractice pressure within our given liability system—captured by the lack of a damage cap—can at most lead to a modest level of deterrence, inconsistent with the idea that the current medical liability system can be used to substantially improve health care quality through deterrent forces.

\footnotetext{
${ }^{14}$ To calculate this percent change (as distinct from a percentage-point change) for the obstetrics measures (which derive from linear probability models on the full delivery subsample), we divide the indicated coefficient by the mean incidence of such measures over the sample. Given the log specification for the AH rate and mortality rate specifications, the coefficient itself can be interpreted in such percentage terms.
} 
In Table C1 of the Online Appendix C, we present dynamic variants of the difference-indifference specifications estimated in Tables $4-7$, which include leads and lags of the damagecap incidence variable, allowing us to explore how the differential in quality across treatment and control states evolves on a year-to-year basis (where time is captured with reference to years before and after adoption). While the confidence bounds for each coefficient in this dynamic specification expand slightly with the inclusion of this additional set of policy variables, they continue to bound zero at a relatively tight rate confirming the conclusion of an at most modest association between damage-cap adoptions and the various quality indicators.

Online Appendix C likewise demonstrates the robustness of these findings to various additional specification checks, including, among others, various alternative constructions of the AH rates and inpatient mortality rates (e.g., the flagging of avoidable hospitalizations using any diagnosis code, not simply the primary diagnosis code) and the consideration only of damagecap adoptions that apply to tort contexts broadly, easing legislative endogeneity concerns—i.e., dropping states that adopted damage caps only in the malpractice context.

Finally, we note that the non-economic damage cap results generalize to the other traditional tort reforms included as covariates, suggesting a generally weak relationship between both inpatient and outpatient health care quality and a broader range of reforms. In the case of the inpatient mortality rate, maternal trauma and preventable delivery complications measures, the results of an F-test of joint significance of all remedy-focused tort measures fail to reject the hypothesis that the coefficients of the various tort reforms are all jointly equal to zero. In the case of the $\mathrm{AH}$ rate specifications, the estimated coefficient of the residual reform category - i.e., the “indirect” reform category specified according to Kessler and McClellan (1996) - is negative and bounded away from zero in some specifications, suggesting an improvement in quality in 
connection with such reforms and thus counter to any expectation that such reforms would relax malpractice pressures to the detriment of patient quality. ${ }^{15}$

The above-estimated specifications include state-year controls for physician concentration rates (and OB/GYN concentration rates in the case of the obstetrics measures). Such controls may absorb any impact of the reforms that occur through changes in the physician population. However, these simple controls may not absorb all supply-related consequences of such reforms. One effect of non-economic damage cap adoptions sometimes hypothesized is that lower-quality physicians may be attracted to the jurisdiction subsequent to the reform (Seabury 2010), a development which could otherwise confound any attempt to isolate the impact of malpractice pressure on the quality provided by any given provider. Of course, to the extent that non-economic damage caps would attract low-quality physicians and lead to a decline in observed quality - e.g., to an increase in the quality indicators explored in Tables $4-7-$ this omission could only help to explain any positive effects of such reforms on the indicators explored. That is, a correction for this bias would likely push the estimated impacts of the reforms on the observed indicators even lower, only lending further support to the claim that liability pressure on the margin within our current liability system does not appear to be substantially improving the quality of care being delivered by physicians.

\section{Cancer Screening Measures}

As presented in Table 8, the pattern of results from the cancer-screening / damage-cap analysis mirrors that from the AHRQ-inspired quality measures (with even greater precision in

\footnotetext{
${ }^{15}$ One component of this residual category is the reform of the joint and several liability rule. In alternative specifications (not shown), where we include the joint and several liability reform independently, we likewise estimate small, negative point estimates for this reform, suggesting an improvement in avoidable hospitalization rates in connection with joint and several liability reforms, perhaps consistent with the predictions set forth in Currie and MacLeod (2008).
} 
the estimates). We estimate mean associations between damage-cap adoptions and the various cancer screening rates that are very nearly zero in magnitude. As above, we cannot rule out some level of reductions in quality—i.e., some reduction in screening rates-in connection with damage cap reforms that are designed to reduce liability pressure. However, the 95-percent confidence bounds for each rate suggest that we can rule out substantial reductions in screening rates in associated with caps. Lower bounds for these intervals suggest a 2.1, 3.0, 4.0, 1.7, 0.2 and 3.2 percent reduction (and an even lower percentage-point reduction) in mammography, physical breast, sigmoidoscopy/colonoscopy, PSA testing, and digital rectal and pap smear examinations, respectively. To simplify the presentation of these results, we present only the results from the naïve difference-in-difference specifications. In Online Appendix C, we demonstrate the robustness of these findings to the addition of a range of control variables, along with alternative constructions of the screening rates.

\section{Alternative Codification of Damage-Cap Variable: Simulation Analysis}

In the final column of each of Tables $4-8$, along with Column 4 of Table 5 , we estimate specifications that take an alternative approach to the codification of the damage-cap incidence variable. While the malpractice literature customarily codifies damage-cap adoptions in a simple binary fashion (0/1), non-economic damage cap provisions, in fact, take on a range of forms across jurisdictions. For instance, California imposes a flat, nominal \$250,000 cap on noneconomic damages awards, while Wisconsin imposes a \$750,000 cap. One might imagine that California's cap would entail a stronger reduction in liability pressure. Hyman et al. (2009) use closed-claims data from Texas during the period of time prior to the imposition of its noneconomic damage cap (where such data contain information on the breakdown of economic versus non-economic damages associated with the claim) to simulate the potential impact of the 
various damage-cap provisions across the various states. More specifically, they simulate the percentage of a mean verdict that is reduced through the imposition of the various caps employed across states.

In the present analysis, we build on these preliminary efforts by Hyman et al. (2009) and use the results of this simulation exercise as the relevant damage-cap variable within the difference-in-difference specification, as opposed to the simple binary approach. In applying these simulated measures to each state-year cell, we appropriately adjust this simulated reduction to account for inflation in the case of those damage-cap provisions that do not tie their cap levels to inflation. This codification scheme is inspired by studies in public finance (including those that codify the degree of Medicaid expansions, Currie and Gruber 1996). It provides an empirically-informed way to ensure the comparability of the legal modifications under investigation, effectively reframing the treatment of the law in terms of the common function provided by such laws (i.e., reducing awards), as opposed to some coarse measure of their existence.

The estimated mean coefficients from those specifications using this alternative codification of damage-cap variables do not differ substantially from those derived from the traditional binary approach. In the case of inpatient mortality rates for selected medical conditions, AH rates, low-discretionary AH rates, maternal trauma rates and preventable delivery complication rates, such estimates suggest a $-0.1,-3.7,-3.0,-0.0$ and -3.0 percent change in the respective quality indicator upon an increase from 0 percent to $100 \%$ in the simulated extent to which a damage cap reduces a jury verdict. These largely negative point estimates are also inconsistent with the expectation that reducing liability pressure through the imposition of a cap will lead to a decline in quality-i.e., an increase in these respective measures. As above, of 
course, these results are statistically insignificant and cannot rule out some degree of a positive association between these measures and the reduction in damage awards resulting from caps. The associated upper ends of the confidence intervals for these estimates suggest a 17.1, 9.3, 6.1, 33.3, and 16.0 percent change respectively. While the upper bounds are larger than those for the traditional codification approach discussed above, bear in mind that these estimates are to be interpreted in terms of a shift in the law that leads to a full $100 \%$ reduction in malpractice verdicts.

\section{B. Liability-Standards Analysis}

\section{AHRQ-Inspired Measures and Preventable Delivery Complications}

The above approach identifies the influence of malpractice law by comparing quality across regimes marked by different levels of expected liability awards. Effectively taking as given the structure of the liability system itself, this initial approach allows us to explore the marginal influence of the present custom-focused liability system. In an alternative approach to exploring the link between malpractice and health care quality, we estimate the interaction specification indicated by equation (2) above and explore whether health care quality is influenced by potentially more impactful reforms that directly alter the clinical standards of care expected of physicians. More specifically, we explore the impact of moving from locality rules to national-standard rules, separating the inquiry into investigations of the effect of nationalstandard adoptions for (1) initially low-quality regions — that is, regions with initially high levels of the AHRQ-inspired measures and of preventable delivery complications and (2) initially highquality regions - that is, regions with initially low levels of the respective indicators. The results of this exercise are presented in Tables $9-12$. 
The coefficients presented in the first row of each of Tables $9-12$ can be interpreted as the association between the given quality indicator and the adoption of a national-standard rule in those treatment states that began the sample period with initially above-average indicator levels (i.e., where the below-average indicator variable equals zero), representing those states with initially low levels of quality. In the case of inpatient mortality rates for our selected medical conditions, the $\mathrm{AH}$ rate, the low-discretionary $\mathrm{AH}$ rate, the maternal trauma rate and the preventable complication rate, we estimate that the adoption of a national-standard rule in such states is associated with a substantial and statistically significant (across nearly every specification) decrease in the respective indicator measure and thus a substantial increase in health care quality (considering, again, that high quality is captured by lower levels of these various indicator measures). More specifically, in the naïve difference-in-difference specifications with only state and year fixed effects, we estimate a 7.6, 47.4, 54.5, 12.6 and 40.3 percent decrease in the respective quality indicator in connection with national-standard adoptions. With the inclusion of various state-year covariates and state-specific linear time trends, these estimates remain nearly the same, suggesting a 9.0, 22.3, 27.2, 28.6, and 42.0 percent decline in the respective indicator. Considering that a national-standard adoption in such initially-low-quality states entails a shift in clinical expectations in the direction of higher quality, the results from this exercise suggest that liability reforms that affirmatively elevate the standards expected of physicians—a reform of a far different variety than damage caps—may indeed succeed in inducing higher quality practices.

In Tables C3 and C4 of Online Appendix C, we present results from dynamic versions of the specifications estimated in Tables $9-12$. For each measure of health care quality, the estimated pattern of lead coefficients for the national-standard indicators do not suggest any 
increasing trends in the differential quality attainments between treatment and controls states prior to the reforms. Pre-treatment trends of that nature may have undermined the assumption inherent in the difference-in-difference specification that, but for the change in the law, the quality indicators would have trended in the same direction in the treatment and control groups alike. As such, the fact that the differential in quality emerges only upon the adoption of the national standard rules themselves increases our confidence in a causal interpretation of the documented associations. Online Appendix $\mathrm{C}$ further demonstrates the robustness of these findings to a number of specification checks, including those listed above for the damage-cap analysis, along with the use of a randomization inference approach to explore the statistical significance of the findings.

While practices appear to improve upon a shift in clinical standards expecting higher quality, the results do not overwhelmingly suggest a corresponding decline in quality upon a shift in legal standards arguably condoning lower quality care. To assess this reverse question, we explore what happens to initially high quality states (states with initially low quality indicator levels) when they adopt national-standard rules, which, in the case of such states, arguably lower operable standards by expecting that physicians follow the lesser-quality practices applied elsewhere. These results can be obtained from the relevant interaction specification by adding the two coefficients presented in the various columns of Tables 9 - 12 (adding the baseline effect in the initially low-quality states to the interaction term capturing the subsequent change in the quality indicator associated with moving towards an initially-high-quality state). Across the various indicators, this addition suggests that a national standard adoption in the initially highquality states is associated with a 5.2, -1.4, -1.1, -4.3 , and an 11 percent change in the respective quality indicator. Only in the case of the inpatient mortality rate and the preventable delivery 
complication rate do we observe a decline in quality-that is, an increase in the respective indicator-upon this change in standards arguably condoning a lower level of quality. Even in those cases, of course, these responses are more modest than the responses indicated above for the initially low-quality states. Further, as demonstrated by Table C4 in Online Appendix, C it appears that the inpatient mortality rate response emerges largely in the period of time prior to the national-standard adoption, suggesting that it may not even be a true response to the law itself.

\section{Cancer Screening Measures}

For this liability standards analysis, our primary tables do not include results for the cancer screening measures. For some of these measures-e.g., PSA testing for prostate cancerdata are only available during the 2000s, affording no ability to draw upon relevant standard-ofcare reforms. Likewise, with respect to sigmoidoscopy/colonoscopy screening for colon cancer, data are generally unavailable in the pre-reform years for the relevant treatment states to facilitate a difference-in-difference analysis. For the remaining cancer screening measures-e.g., those relating to breast and cervical cancer—data are available during a period of time-i.e., the 1990s_ - in which Indiana, Delaware and Rhode Island can be utilized as treatment states. Our intent, of course, is to separately test for the effect of national-standard adoptions for those treatment states with initially high and initially low cancer screening rates. ${ }^{16}$ For the breastcancer-screening measures, this leaves only one state-Indiana-from which to explore the effect of a liability reform that entails a heightening of standards. In the case of pap smear testing, both Indiana and Rhode Island can be utilized as treatment states in exploring the effect of heightened standards. In either case, with only one or two treatment states, the point estimates

\footnotetext{
${ }^{16}$ Following Frakes (2013), we exclude from this initially-high versus initially-low analysis the state of Maryland, which modified its standard of care laws over the 1990s to retreat from a previous national-standard adoption, insofar as it is difficult to hypothesize the direction in which practices will evolve subsequent to this retreat.
} 
from a difference-in-difference analysis are generally thought to be inconsistent (Conley and Taber 2011), leaving us with arguably unreliable estimates (given a higher degree of chance that spurious developments explain the findings). As such, we do not include them alongside the primary results from this analysis, which draw upon much more extensive legal variation. Nonetheless, we present such results in Online Appendix C. Encouragingly, such results likewise document an increase in quality attainment (in this case, an increase in cancer screening rates) upon a modification of standard-of-care rules that entail a heightening of expectations.

\section{DISCUSSION AND CONCLUSION}

An extensive number of empirical malpractice studies have endeavored to test for the existence and scope of so-called "defensive medicine." While deterrence of medical errors can be viewed as a primary objective of the medical liability system, defensive-medicine is best characterized as a possibly unfortunate side-effect / cost of this system. Physicians may act defensively when they unnecessarily order costly tests, procedures and visits over fear of malpractice liability (OTA 1994). However, even if one's primary focus is to explore these side effects of liability, rather than to assess whether the law is achieving its stated goal of deterring medical errors, it is critical to bear in mind that labeling a response as "defensive" requires more than a mere understanding of whether liability encourages additional utilization of medical care. Since a defensive response is defined with reference to the necessity (or optimality) of the chosen level of treatment, this assessment requires a determination as to whether or not any malpractice-induced expansion in treatment is accompanied by corresponding improvements in quality or outcomes.

As such, whether the goal is to make an independent evaluation of the deterrent impact of medical liability or to properly diagnose a defensive response to liability, it is necessary to 
estimate the impact of the malpractice system on medical errors and health care quality. To date, however, nearly all studies which assess the impact of malpractice pressure on health care quality focus on coarse measures of quality such as aggregate mortality rather than more direct measures of physician behavior. A major contribution of our analysis is to use clinically validated measures of health care quality to estimate the effect of malpractice pressure on the quality of care provided by physicians. In this process, it is also important to bear in mind the structure of the malpractice system itself, a factor generally overlooked in most empirical discussions of this nature. In estimating the impacts of remedy-focused / non-substantive reforms such as non-economic damage caps, one is effectively teasing out the marginal impacts of the present structure of liability. The confidence bounds presented in our analysis suggest, at most, a modest degree of deterrence stemming from the present liability system. The mean point estimates suggest that this system generates little to no benefits in health care quality. We caution that these findings should perhaps not be interpreted so as to suggest that medical liability forces are universally incapable of improving quality. Rather, they should be interpreted in light of the largely self-regulatory nature of our present malpractice system.

Given the malpractice system's strong adherence to customary physician practices, practices which are themselves shaped through a variety of non-legal influences, it is perhaps unsurprising that when we roll back the force of the law through damage-cap-esque reforms we do not find ourselves in a situation where physicians face significantly weakened incentives to deliver quality care. The law itself is not designed to impose independent expectations regarding quality. Of course, the law may still elevate care to the extent that it discourages errant physicians seeking to deviate from industry custom. Even in such instances, however, it is important to bear in mind that customary physician practices themselves fall far short in 
promising the delivery of high quality care (e.g., rates of age appropriate cancer screening fall well below 100\%), in which event legal enforcement of such custom will similarly fail to hold much promise. Finally, while the threat to physicians that courts may imperfectly judge their behavior relative to the standard of care may cause physicians to attempt to outperform industry custom, they are necessarily provided with no guidance as to how achieve that end.

The second half of our empirical analysis provides some hope, however, in the potential for medical liability to influence physician behavior. Drawing upon the one type of standard-ofcare reform that states have experimented with to date-i.e., locality rule abdications-we investigate the impact of changing the clinical standards of care imposed upon physicians under the law, both in terms of elevated standards and slackened standards. All told, it appears that the relationship between health care quality and changes in clinical malpractice standards works in an expansionary direction only. That is, once physicians provide a high level of quality, they may maintain such practices even when the law may loosen its expectations at a later date. In contrast, physicians who provide a quality of care that is below what is expected by the law raise their practice to meet the higher expectations set by the law. Malpractice forces may therefore be effective in elevating the quality floor. This pattern of results is arguably consistent with an interpretation in which informational forces constitute the mechanism of action behind any responsiveness in behavior to legal standards, as hypothesized above and as distinct from traditionally hypothesized fear-of-liability channels. Further work, however, is warranted to tease out the underlying story behind such responses and to distinguish informational mechanisms from traditional fear-based liability mechanisms.

If our findings are taken to suggest that structural reforms to the way in which physicians are evaluated may substantially alter health care delivery practices, one may wonder whether 
subsequent reforms that blunt the impact of the now altered liability system-e.g., damage caps-may cause practices to revert back to where they were before the structural reforms. Informational considerations may likewise suggest why this may not be so. If physicians, especially newer physicians, form beliefs over proper practices to a large extent through their own past experiences or through the observation of the practices followed by others around them (Phelps and Mooney 1993), then a shift in medical practices that arises in any manner—even that arising from fear over being out of compliance with changed legal expectations-may more gradually come to be assimilated into the belief structure of physicians over time. As such, malpractice-induced changes in practices may come to shape more durable physician norms and customs that may survive subsequent diminishment of liability forces. These considerations may thus help us understand why damage cap adoptions-which primarily arose in states after previous retreats from the locality rule—did not cause physician practices to revert back to their locality-rule-era levels.

Empirical malpractice investigations that fail to consider the equilibrium reached between liability forces and non-liability forces over time, and that fail to appreciate the structural considerations underlying tort law, may misinterpret the findings derived from our experiences to date with traditional remedy-centric tort reforms. Such findings may suggest only a weak responsiveness to the law despite a potentially meaningful role for the law to play in shaping clinical practices and health care quality. Substantial work remains, of course, to understand the liability structure that will best serve society. Our analysis demonstrates that it would be premature to rule out medical liability from the health care quality discussion based on the limited findings that derive from damage-cap-focused studies.

\section{REFERENCES}


Baicker, Katherine, Elliot Fisher, and Amitabh Chandra. 2007. Malpractice Liability Costs And The Practice Of Medicine In The Medicare Program. Health Affairs, 26, 841-52.

Blumstein, James. 2002. The Legal Liability Regime: How Well is it Doing in Assuring Quality, Accounting for Costs, and Coping with an Evolving Reality in the Health Care Marketplace. Annals of Health Law 11, 125-146.

Blumstein, James. 2006. Medical Malpractice Standard-Setting: Developing Malpractice “Safe Harbors” as a new Role for QIOs? Vanderbilt Law Review 59, 1017 - 1049.

Carter, Mary. Variations in Hospitalization Rates among Nursing Home Residents: The Role of Discretionary Hospitalizations. Health Services Research 38, 1177-1206.

Casey, Brian M., Donald D. McIntire, and Kenneth J. Leveno. 2001. The continuing value of the Apgar score for the assessment of the newborn infants. New England Journal of Medicine 344, $467-71$.

Centers for Medicare and Medicaid Services. 2010. National Health Expenditure Accounts: Tables. Available at: http://www.cms.gov/Research-Statistics-Data-and-Systems/StatisticsTrends-and-Reports/NationalHealthExpendData/Downloads/tables.pdf (accessed June, 17 2012).

Chandra, Amitabh, and Douglas O. Staiger. 2007. Productivity Spillovers in Healthcare: Evidence From the Treatment of Heart Attacks. Journal of Political Economy 115, 103-40.

Cohen, Thomas. 2005. Punitive Damage Awards in Large Counties, 2001. Bureau of Justice Statistics Selected Findings.

Conley, Timothy, and Christopher Taber. 2011. Inference with 'Difference-in-Differences' with a Small Number of Policy Changes. The Review of Economics and Statistics 1, 113-25.

Currie, Janet, and W. Bentley MacLeod. 2008. First Do No Harm? Tort Reform and Birth Outcomes. Quarterly Journal of Economics 123, 795-830.

Dafny, Leemore, and Jonathan Gruber. 2005. Public Insurance and Child Hospitalizations: Access and Efficiency Effects. Journal of Public Economics 89, 109-29.

Dubay, Lisa, Robert Kaestner, and Timothy Waidmann. 1999. The Impact of Malpractice Fears on Cesarean Section Rates. Journal of Health Economics 18, 491-522.

Frakes, Michael. 2012. Defensive Medicine and Obstetric Practices. Journal of Empirical Legal Studies, forthcoming. 
Frakes, Michael. 2013. The Impact of Medical Liability Standards on Regional Variations in Physician Behavior: Evidence from the Adoption of National-Standard Rules. American Economic Review, forthcoming.

Greenberg, Michael D., Amelia M. Haviland, J. Scott Ashwood, and Regan Main. 2010. Is better patient safety associated with less malpractice activity? Evidence from California. Santa Monica: RAND Institute for Civil Justice.

Hyman, David, Bernard Black, Charles Silver \& William Sage. 2009. Estimating The Effect of Damage Caps in Medical Malpractice Cases: Evidence from Texas. Journal of Legal Analysis 1, 355-409.

Iizuka, Toshiaki. 2013. Does Higher Malpractice Pressure Deter Medical Errors? 56 Journal of Law and Economics 1, 161-88.

Institute of Medicine Committee on Quality of Health Care in America. 2000. To Err Is Human: Building a Safer Health System. Washington, D.C.: National Academy Press.

Jena, Anupam, Seth Seabury, Darius Lakdawalla, and Amitabh Chandra. 2011. Malpractice Risk according to Physician Specialty. New England Journal of Medicine 365, 629-636.

Kessler, Daniel, and Mark McClellan. 1996. Do Doctors Practice Defensive Medicine? Quarterly Journal of Economics 111, 353-90.

Klick, Jonathan, and Thomas Stratmann. 2007. Medical Malpractice Reform and Physicians in High-Risk Specialties. Journal of Legal Studies 36, S121-S142.

Lakdawalla, Darius, and Seth Seabury. 2009. The Welfare Effects of Medical Malpractice Liability. NBER Working Paper No. 15383.

Localio, A. Russell, Ann Lawthers, Troyen Brennan, Nan Laird, Liesi Hebert, Lynn Peterson, Joseph Newhouse, Paul Weiler, and Howard Hiatt. 1991. Relation between malpractice claims and adverse events due to negligence: results of the Harvard Medical Practice Study III. New England Journal of Medicine 325, 245-51.

Malani, Anup, and Julian Reif. Accounting for Anticipation Effects: An Application to Medical Malpractice Tort Reform. NBER Working Paper No. 16593.

McClellan, Mark, and Douglas Staiger. 1999. The Quality of Health Care Providers. NBER Working Paper No. 7327.

McGlynn, Elizabeth A., Steven M. Asch, John Adams, Joan Keesey, Jennifer Hicks, Alison DeCristofaro, and Eve A. Kerr. 2003. The Quality of Health Care Delivered to Adults in the United States. New England Journal of Medicine 348, 2635-2645. 
Mello, Michelle M. 2006. Medical Malpractice: Impact of the Crisis and Effect of State Tort Reforms. Research Synthesis Report \#10. New Brunswick, NJ: Robert Wood Johnson Foundation.

Mello, Michelle M., and Troyen A. Brenan. 2002. Deterrence of Medical Errors: Theory and Evidence for Malpractice Reform. Texas Law Review 80, 1595-1637.

Mello, Michelle M. and Allen Kachalia. 2010. Evaluation of options for medical malpractice system reform: a report to the Medicare Payment Advisory Commission, (MedPAC, 2010), available at http://www.medpac.gov/documents/Apr10_MedicalMalpractice_

CONTRACTOR.pdf.

Mello, Michelle M., David M. Studdert, Catherine M. DesRoches, Jordon Peugh, Kinga Zapert, Troyen A. Brennan, and William M. Sage. 2005. Effects of a Malpractice Crisis on Specialist Supply and Patient Access to Care. Annals of Surgery 242, 621-628.

National Center for Health Statistics. 1977-2005. National Hospital Discharge Survey. Centers for Disease Control and Prevention (last accessed at NCHS Research Data Center on January 31, 2012).

Office of Technology Assessment. 1994. Defensive Medicine and Medical Malpractice. OTAH--6O2.

Paik, Myungho, Bernard Black and David Hyman. 2013. The Receding Tide of Medical Malpractice Litigation Part 2: Effect of Damage Caps. Journal of Empirical Legal Studies, forthcoming.

Peters, Phillip. 2008. Resuscitating Hospital Enterprise Liability. 73 Missouri Law Review 369, 369-97.

Schiff, Gordon, Ann Louise Puopolo, Anne Huben-Kearney, Winnie Yu, Carol Keohane, Peggy McDonough, Bonnie R. Ellis, David W. Bates, and Madeleine Biondolillo. 2013. Primary Care Closed Claims Experience of Massachusetts Malpractice Insurers. JAMA Internal Medicine, forthcoming.

Seabury, Seth. 2010. Does Malpractice Liability Reform Attract High Risk Doctors? RAND Working Paper No. WR-674-ICJ.

Sloan, Frank A., and John H. Shadle. Is there empirical evidence for "Defensive Medicine”? A reassessment. Journal of Health Economics 28, 481-491.

Studdert, David M., Michelle M. Mello, Atul A. Gawande, Tejal K. Ghandi, Allen Kachalia, Catherine Yoon, Ann Louise Puopolo and Troyen A. Brennan. 2006. Claims, Errors, and Compensation Payments in Medical Malpractice Litigation. New England Journal of Medicine 354, 2024-2033. 
Wennberg, John E. 1984. Dealing With Medical Practice Variations: A Proposal for Action. Health Affairs 3, 6-32.

Wennberg, John E., and Megan McAndrew Cooper (Eds.). 1999. The Quality of Medical Care in the United States: A Report on the Medicare Program. The Dartmouth Atlas of Health Care in the United States. Chicago: American Health Association Press.

Weissman, Joel S., Constantine Gatsonis, and Arnold Epstein. 1992. Rates of Avoidable Hospitalization by Insurance Status in Massachusetts and Maryland. JAMA 268, 2388-2394.

Zabinski, Zenon and Bernard Black. 2013. The Effect of Tort Reform on Patient Safety: Evidence from Texas.

Zeiler, Kathryn, Charles Silver, Bernard Black, David Hyman, and William Sage. 2007. Physicians' Insurance Limits and Malpractice Payments: Evidence from Texas Closed Claims, 1990-2003. Journal of Legal Studies 36, S9-S45. 
Figure 1

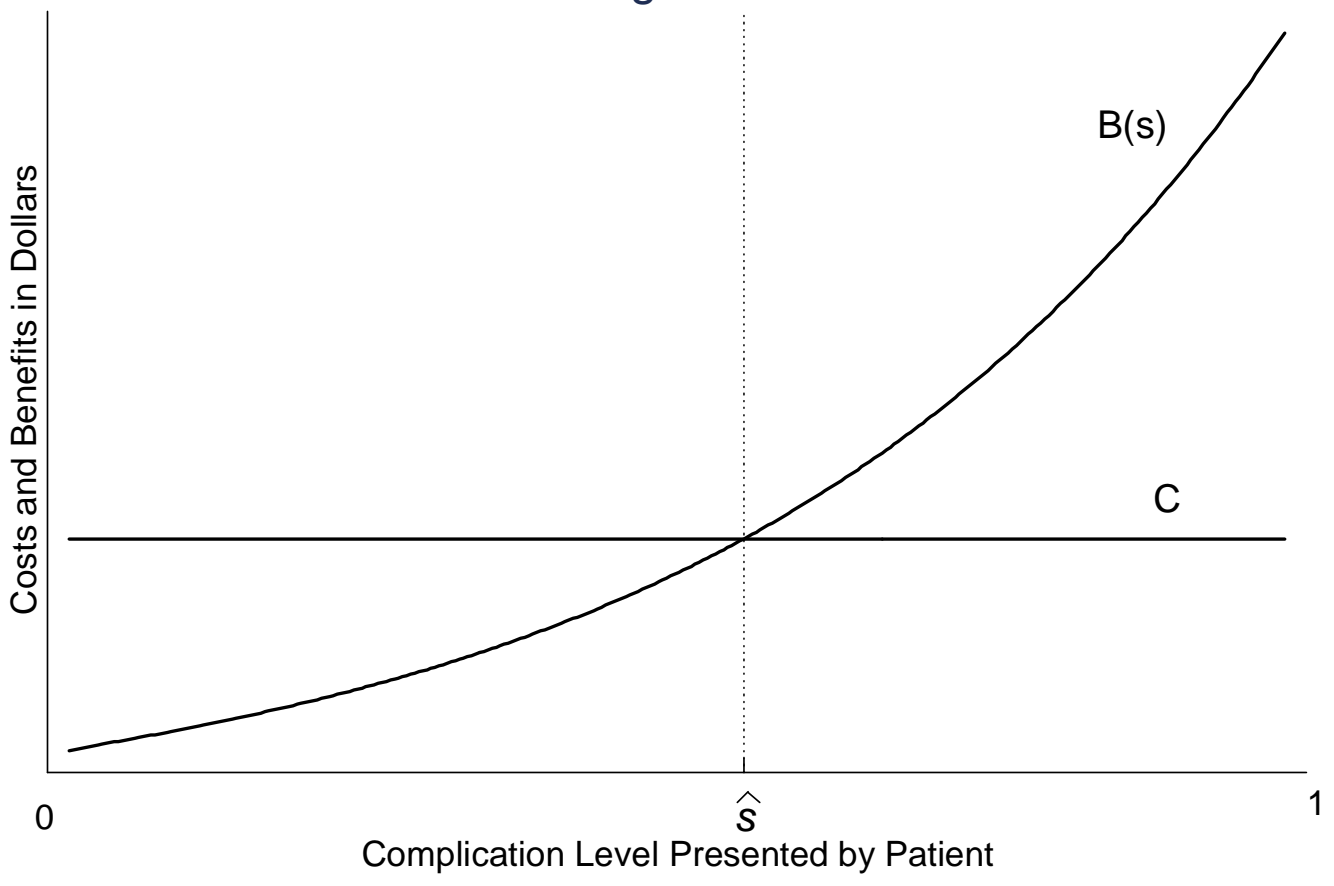

Figure 2

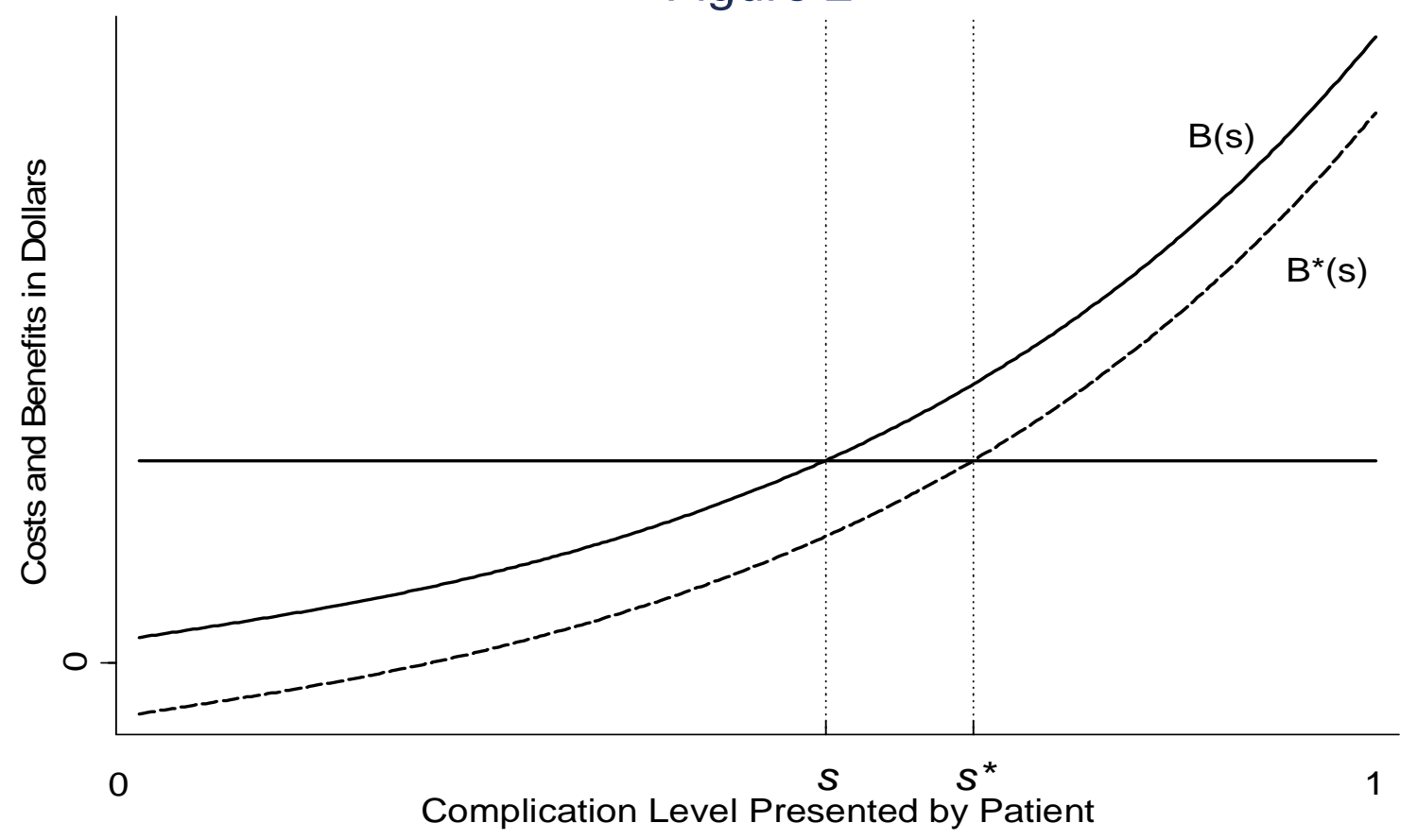


Table 1. Variations in Non-Economic Damage Caps (1979-2005)

\begin{tabular}{lll|lll}
\hline State & Year Adopted & Year Dropped & State & Year Adopted & Year Dropped \\
\hline Alaska & 1986 & \multirow{2}{*}{1992} & Mississippi & 2003 & 1996 \\
Alabama & 1987 & & Montana & 1996 & $1981(1) ; 1991(2)$ \\
Colorado & 1987 & & North Dakota & $1987(2)$ & $1992(1)$ \\
Florida & 2004 & & New Hampshire & $1983(2)$ & 2000 \\
Hawaii & 1987 & \multirow{2}{*}{1998} & Ohio & 2003 & $1988(1)$ \\
Idaho & 1988 & & Oklahoma & 2004 & 1988 \\
Illinois & 1995 & & Oregon & $2004(2)$ & 1990 \\
Kansas & 1987 & & Utah & 1988 & 1986 \\
Massachusetts & 1987 & & Washington & 1986 & 1986 \\
Maryland & 1987 & & Wisconsin & \\
Michigan & 1987 & \multirow{2}{*}{1990} & West Virginia & & \\
Minnesota & 1986 & & & \\
Missouri & 1986 & & &
\end{tabular}

Notes: years of adoption and invalidation/repeal (if applicable) of laws imposing caps on non-economic damage awards in malpractice cases (or tort cases generally) are indicated above. States are only included if their relevant malpractice laws varied over the 1979 - 2005 period. Legislative variation is excluded from this table if it represents a situation in which an adoption and invalidation/repeal occurred during the same year. Source: Database of State Tort Law Reforms (2nd).

Table 2. Variations in National-Standard Rules (1979-2005)

\begin{tabular}{|c|c|c|c|c|c|}
\hline State & Year Adopted & Year Dropped & State & Year Adopted & Year Dropped \\
\hline Alabama & 1980 & & Montana & 1985 & \\
\hline Colorado & 1983 & & Oklahoma & 1984 & \\
\hline Connecticut & 1984 & & Rhode Island & 1998 & \\
\hline Delaware & 1999 & & South Carolina & 1981 & \\
\hline D.C. & 1980 & & South Dakota & 1988 & \\
\hline Indiana & 1992 & & West Virginia & 1986 & \\
\hline Maryland & & 1994 & Wyoming & 1981 & \\
\hline Mississippi & 1983 & & & & \\
\hline
\end{tabular}

Notes: years of adoption and repeal (if applicable) of laws requiring that physicians follow national (as opposed to local) standards of care in malpractice actions. States are only included if their relevant malpractice laws varied within the $1979-2005$ period. Source: Frakes (2013). 
Table 3. Descriptive Statistics

Percentage Absolute

Mean (Standard Deviation)

Deviation between State and

National Mean

\section{Panel A: Quality Measures (NHDS)}

Composite Inpatient Mortality Rate

0.08

0.16

$(0.03)$

Avoidable Hospitalization Rate

(Avoidable Hospitalizations Scaled by

1.70

0.17

Low-Variation Health Index)

(0.42)

Low-Discretionary Avoidable

1.00

0.15

Hospitalization Rate

(0.23)

Maternal Trauma Rate

Maternal Preventable Complications

0.16

0.20

Rate

(0.06)

$(0.20)$

\section{Panel B: Cancer-Screening Rates} (BRFSS)

Mammogram (within last year, female

age 40-75)

Physical breast exam (within last year, female age 40-75)

Proctoscopic exam (sigmoidoscopy or colonoscopy within last 5 years, age 50-75)

PSA Testing (within last year, age 50-

75)

Digital Rectal Exam for Prostate

Pap smear (within last year, age 21+)

Notes: Standard deviations are in parentheses. Quality measures in Panel A are from a sample of 1190 state-year cells from the 1979 - 2005 NHDS files. Quality statistics in Panel A are weighted by the relevant denominator used in the state-year quality rate (e.g., the state-year delivery count or the state-year low-variation health index).

Source: Panel A: National Hospital Discharge Survey (1979-2005), Panel B: Behavioral Risk Factor Surveillance System (1987-2008). 
Table 4: Relationship between Remedy-Centric Tort Reforms and Inpatient Mortality Rate

for Selected Conditions (Logged, Risk-Adjusted)

\begin{tabular}{lcccc}
\hline & $(1)$ & $(2)$ & $(3)$ & $(4)$ \\
\hline & & & & \\
Non-Economic Damage Cap & 0.008 & -0.012 & -0.038 & - \\
Damage Cap Strength: & $(0.030)$ & $(0.028)$ & $(0.030)$ & -0.001 \\
$\quad$ Simulated Percentage & - & & & $(0.086)$ \\
$\quad$ Decline in Mean Verdict & & - & - & 0.013 \\
Collateral Source Rule Reform & - & 0.015 & 0.014 & $(0.023)$ \\
& & $(0.025)$ & $(0.041)$ & 0.001 \\
Punitive Damage Cap & - & -0.001 & 0.006 & $0.038)$ \\
& & $(0.038)$ & $(0.047)$ & 0.003 \\
"Indirect” Tort Law & - & 0.009 & $(0.027)$ & $(0.029)$ \\
\hline 95\% Confidence Band for Coefficient & {$[-0.052$,} & {$[-0.068$,} & {$[-0.099$,} & {$[-0.172$,} \\
of Non-Economic Damage Cap & $0.066]$ & $0.043]$ & $0.022]$ & {$[0.171]$} \\
Variable & - & 0.15 & 0.49 & 0.10 \\
\hline F-Statistic (Malpractice Variables & - & 0.96 & 0.74 & 0.98 \\
Jointly = 0) & NO & YES & YES & YES \\
Prob > F (p value) & NO & NO & YES & YES \\
\hline Control Variables? & 1154 & 1141 & 1141 & 1141 \\
\hline State-Specific Linear Trends? & N & & & \\
\hline
\end{tabular}

Notes: robust standard errors corrected for within-state correlation in the error term are reported in parentheses. All regressions included state and year fixed effects and are weighted by the number of admissions (for the relevant state and year) in the sub-sample of discharges associated with the selected conditions (i.e., the sum of discharges for acute myocardial infarction, heart failure, acute stroke, gastrointestinal bleeding, hip fracture or pneumonia). Mortality rates are risk-adjusted for the incidence (among the sub-sample) of each of the conditions comprising the sub-sample of selected conditions.

Source: 1979 - 2005 National Hospital Discharge Surveys.

*** Significant at the 1 percent level.

** Significant at the 5 percent level.

* Significant at the 10 percent level. 
Table 5. Relationship between Remedy-Centric Tort Reforms and Avoidable Hospitalization Rates (Logged)

\begin{tabular}{|c|c|c|c|c|c|c|c|c|}
\hline & $(1)$ & $(2)$ & (3) & (4) & $(5)$ & (6) & (7) & (8) \\
\hline & \multicolumn{4}{|c|}{$\begin{array}{c}\text { RATES BASED ON ALL AVOIDABLE } \\
\text { HOSPITALIZATIONS }\end{array}$} & \multicolumn{4}{|c|}{$\begin{array}{l}\text { RATES BASED ON LOW-DISCRETIONARY } \\
\text { AVOIDABLE HOSPITALIZATIONS }\end{array}$} \\
\hline Non-Economic Damage Cap & $\begin{array}{c}0.003 \\
(0.023)\end{array}$ & $\begin{array}{l}-0.016 \\
(0.026)\end{array}$ & $\begin{array}{l}-0.010 \\
(0.029)\end{array}$ & - & $\begin{array}{l}-0.005 \\
(0.024)\end{array}$ & $\begin{array}{l}-0.023 \\
(0.023)\end{array}$ & $\begin{array}{l}-0.017 \\
(0.024)\end{array}$ & - \\
\hline $\begin{array}{l}\text { Damage Cap Strength: } \\
\text { Simulated Percentage } \\
\text { Decline in Mean Verdict }\end{array}$ & - & 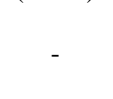 & - & $\begin{array}{l}-0.037 \\
(0.064)\end{array}$ & - & - & - & $\begin{array}{l}-0.030 \\
(0.045)\end{array}$ \\
\hline Collateral Source Rule Reform & - & $\begin{array}{c}0.020 \\
(0.026)\end{array}$ & $\begin{array}{c}0.012 \\
(0.032)\end{array}$ & $\begin{array}{c}0.019 \\
(0.027)\end{array}$ & - & $\begin{array}{c}0.007 \\
(0.024)\end{array}$ & $\begin{array}{c}0.018 \\
(0.034)\end{array}$ & $\begin{array}{c}0.004 \\
(0.024)\end{array}$ \\
\hline Punitive Damage Cap & - & $\begin{array}{c}0.032 \\
(0.033)\end{array}$ & $\begin{array}{l}-0.012 \\
(0.036)\end{array}$ & $\begin{array}{c}0.033 \\
(0.032)\end{array}$ & - & $\begin{array}{c}0.002 \\
(0.029)\end{array}$ & $\begin{array}{l}-0.014 \\
(0.040)\end{array}$ & $\begin{array}{c}0.004 \\
(0.028)\end{array}$ \\
\hline "Indirect” Tort Law & - & $\begin{array}{l}-0.082 \\
(0.049) \\
\end{array}$ & $\begin{array}{c}-0.067 * * \\
(0.032) \\
\end{array}$ & $\begin{array}{c}-0.083 \\
(0.050)\end{array}$ & - & $\begin{array}{r}-0.077^{*} \\
(0.043) \\
\end{array}$ & $\begin{array}{c}-0.076^{* *} \\
(0.028) \\
\end{array}$ & $\begin{array}{l}-0.081^{*} \\
(0.042) \\
\end{array}$ \\
\hline $\begin{array}{l}\text { 95\% Confidence Band for } \\
\text { Coefficient of Non-Economic } \\
\text { Damage Cap Variable }\end{array}$ & $\begin{array}{c}{[-0.044,} \\
0.049]\end{array}$ & $\begin{array}{c}{[-0.069} \\
0.037]\end{array}$ & $\begin{array}{c}{[-0.068} \\
0.048]\end{array}$ & $\begin{array}{c}{[-0.167} \\
0.093]\end{array}$ & $\begin{array}{c}{[-0.052} \\
0.043]\end{array}$ & $\begin{array}{c}{[-0.069,} \\
0.023]\end{array}$ & $\begin{array}{c}{[-0.067,} \\
0.023]\end{array}$ & $\begin{array}{r}{[-0.122,} \\
0.061]\end{array}$ \\
\hline $\begin{array}{l}\text { F-Statistic (Malpractice } \\
\text { Variables Jointly = 0) }\end{array}$ & - & 1.28 & 1.89 & 1.45 & - & 2.17 & 3.43 & 2.51 \\
\hline Prob > F (p value) & - & 0.29 & 0.13 & 0.23 & - & 0.086 & 0.015 & 0.054 \\
\hline Control Variables? & NO & YES & YES & YES & NO & YES & YES & YES \\
\hline State-Specific Linear Trends? & NO & NO & YES & YES & NO & NO & YES & YES \\
\hline $\mathrm{N}$ & 1190 & 1177 & 1177 & 1177 & 1190 & 1177 & 1177 & 1177 \\
\hline
\end{tabular}

Notes: robust standard errors corrected for within-state correlation in the error term are reported in parentheses. All regressions included state and year fixed effects and are weighted by the low-variation health index (i.e., the sum of discharges for acute myocardial infarction, stroke, hip fracture or gastrointestinal bleeding) associated with each stateyear cell. The low-variation index constitutes the denominator for the relevant avoidable hospitalization rate.

Source: 1979 - 2005 National Hospital Discharge Surveys.

*** Significant at the 1 percent level.

** Significant at the 5 percent level.

* Significant at the 10 percent level. 
Table 6: Relationship between Tort Reforms and the Incidence of Maternal Trauma among Individual Sample of Deliveries

\begin{tabular}{|c|c|c|c|c|}
\hline & (1) & $(2)$ & (3) & (4) \\
\hline Non-Economic Damage Cap & $\begin{array}{l}-0.001 \\
(0.002)\end{array}$ & $\begin{array}{l}-0.002 \\
(0.003)\end{array}$ & $\begin{array}{l}-0.000 \\
(0.004)\end{array}$ & - \\
\hline $\begin{array}{l}\text { Damage Cap Strength: } \\
\text { Simulated Percentage } \\
\text { Decline in Mean Verdict }\end{array}$ & 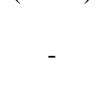 & 5 & - & $\begin{array}{l}-0.000 \\
(0.008)\end{array}$ \\
\hline Collateral Source Rule Reform & - & $\begin{array}{c}0.001 \\
(0.004)\end{array}$ & $\begin{array}{c}0.001 \\
(0.004)\end{array}$ & $\begin{array}{c}0.001 \\
(0.004)\end{array}$ \\
\hline Punitive Damage Cap & - & $\begin{array}{l}-0.005 \\
(0.003)\end{array}$ & $\begin{array}{l}-0.006 \\
(0.004)\end{array}$ & $\begin{array}{l}-0.004 \\
(0.003)\end{array}$ \\
\hline "Indirect” Tort Law & - & $\begin{array}{c}0.003 \\
(0.004)\end{array}$ & $\begin{array}{l}-0.000 \\
(0.004)\end{array}$ & $\begin{array}{c}0.002 \\
(0.004)\end{array}$ \\
\hline $\begin{array}{l}\text { 95\% Confidence Band for Coefficient of Non- } \\
\text { Economic Damage Cap Variable }\end{array}$ & $\begin{array}{c}{[-0.005,} \\
0.003]\end{array}$ & $\begin{array}{c}-0.008 \\
0.003]\end{array}$ & $\begin{array}{c}{[-0.007} \\
0.007]\end{array}$ & $\begin{array}{r}{[-0.016,} \\
0.015]\end{array}$ \\
\hline $\begin{array}{l}\text { 95\% Confidence Band, scaled by mean trauma } \\
\text { incidence }\end{array}$ & $\begin{array}{c}-0.115, \\
0.057]\end{array}$ & $\begin{array}{c}{[-0.180} \\
0.073]\end{array}$ & $\begin{array}{c}{[-0.162} \\
0.151]\end{array}$ & $\begin{array}{c}-0.356, \\
0.333]\end{array}$ \\
\hline F-Statistic (Malpractice Variables Jointly = 0) & - & 0.50 & 1.06 & 1.14 \\
\hline Prob > F (p value) & - & 0.73 & 0.38 & 0.35 \\
\hline Control Variables? & NO & YES & YES & YES \\
\hline State-Specific Linear Trends? & NO & NO & YES & YES \\
\hline $\mathrm{N}$ & 737193 & 565201 & 565201 & 565201 \\
\hline
\end{tabular}

Source: 1979 - 2005 National Hospital Discharge Surveys.

$* * *$ Significant at the 1 percent level.

** Significant at the 5 percent level.

* Significant at the 10 percent level. 
Table 7: Relationship between Remedy-Centric Tort Reforms and the Incidence

of Preventable Delivery Complications among Individual Sample of Deliveries

\begin{tabular}{|c|c|c|c|c|}
\hline & (1) & (2) & (3) & (4) \\
\hline Non-Economic Damage Cap & $\begin{array}{l}-0.002 \\
(0.006)\end{array}$ & $\begin{array}{c}0.005 \\
(0.006)\end{array}$ & $\begin{array}{c}0.007 \\
(0.008)\end{array}$ & - \\
\hline $\begin{array}{l}\text { Damage Cap Strength: } \\
\text { Simulated Percentage } \\
\text { Decline in Mean Verdict }\end{array}$ & - & - & - & $\begin{array}{l}-0.005 \\
(0.015)\end{array}$ \\
\hline Collateral Source Rule Reform & - & $\begin{array}{l}-0.008 \\
(0.008)\end{array}$ & $\begin{array}{l}-0.003 \\
(0.010)\end{array}$ & $\begin{array}{l}-0.006 \\
(0.008)\end{array}$ \\
\hline Punitive Damage Cap & - & $\begin{array}{l}-0.004 \\
(0.006)\end{array}$ & $\begin{array}{l}-0.005 \\
(0.007)\end{array}$ & $\begin{array}{l}-0.005 \\
(0.007)\end{array}$ \\
\hline “Indirect” Tort Law & - & $\begin{array}{l}-0.000 \\
(0.008)\end{array}$ & $\begin{array}{c}0.002 \\
(0.010)\end{array}$ & $\begin{array}{c}0.001 \\
(0.001)\end{array}$ \\
\hline $\begin{array}{l}\text { 95\% Confidence Band for } \\
\text { Coefficient of Non-Economic } \\
\text { Damage Cap Variable }\end{array}$ & $\begin{array}{c}{[-0.014} \\
0.011]\end{array}$ & $\begin{array}{c}{[-0.007} \\
0.017]\end{array}$ & $\begin{array}{c}{[-0.009} \\
0.023]\end{array}$ & $\begin{array}{c}{[-0.035} \\
0.026]\end{array}$ \\
\hline $\begin{array}{l}95 \% \text { Confidence Band, scaled } \\
\text { by mean trauma incidence }\end{array}$ & $\begin{array}{c}{[-0.086,} \\
0.068] \\
\end{array}$ & $\begin{array}{c}-0.043, \\
0.105] \\
\end{array}$ & $\begin{array}{c}-0.056, \\
0.142] \\
\end{array}$ & $\begin{array}{c}{[-0.216} \\
0.160] \\
\end{array}$ \\
\hline $\begin{array}{l}\text { F-Statistic (Malpractice } \\
\text { Variables Jointly }=0 \text { ) }\end{array}$ & - & 0.50 & 0.44 & 0.26 \\
\hline Prob > F (p value) & - & 0.74 & 0.78 & 0.90 \\
\hline Control Variables? & NO & YES & YES & YES \\
\hline $\begin{array}{l}\text { State-Specific Linear Trends? } \\
\mathrm{N}\end{array}$ & $\begin{array}{c}\text { NO } \\
737193\end{array}$ & $\begin{array}{l}\text { NO } \\
566249\end{array}$ & $\begin{array}{c}\text { YES } \\
566249\end{array}$ & $\begin{array}{c}\text { YES } \\
566249\end{array}$ \\
\hline \multicolumn{5}{|c|}{$\begin{array}{l}\text { Notes: robust standard errors corrected for within-state correlation in the } \\
\text { error term are reported in parentheses. All regressions included state and } \\
\text { year fixed effects. } \\
\text { Source: } 1979-2005 \text { National Hospital Discharge Surveys. } \\
\text { *** Significant at the } 1 \text { percent level. } \\
\text { ** Significant at the } 5 \text { percent level. } \\
\text { * Significant at the } 10 \text { percent level. }\end{array}$} \\
\hline
\end{tabular}


Table 8: Relationship between Remedy-Centric Tort Reforms and Cancer Screening Rates

\begin{tabular}{|c|c|c|c|c|c|c|}
\hline & (1) & (2) & (3) & (4) & (5) & (6) \\
\hline & $\begin{array}{c}\text { MAMMO- } \\
\text { GRAM }\end{array}$ & $\begin{array}{l}\text { PHYSICAL } \\
\text { BREAST } \\
\text { EXAM }\end{array}$ & $\begin{array}{l}\text { PROCTO- } \\
\text { SCOPIC } \\
\text { EXAM }\end{array}$ & $\begin{array}{c}\text { PSA } \\
\text { TESTING }\end{array}$ & $\begin{array}{l}\text { DIGITAL } \\
\text { RECTAL } \\
\text { EXAM }\end{array}$ & $\begin{array}{c}\text { PAP } \\
\text { SMEAR }\end{array}$ \\
\hline Non-Economic Damage Cap & $\begin{array}{c}-0.003 \\
(0.006)\end{array}$ & $\begin{array}{c}-0.005 \\
(0.007)\end{array}$ & $\begin{array}{c}-0.006 \\
(0.005) \\
\end{array}$ & $\begin{array}{c}0.002 \\
(0.006) \\
\end{array}$ & $\begin{array}{c}0.014 \\
(0.008) \\
\end{array}$ & $\begin{array}{c}-0.007 \\
(0.006)\end{array}$ \\
\hline $\begin{array}{l}\text { 95\% Confidence Band for } \\
\text { Coefficient of Non- } \\
\text { Economic Damage Cap } \\
\text { Variable }\end{array}$ & $\begin{array}{c}{[-0.015} \\
0.008]\end{array}$ & $\begin{array}{c}{[-0.019} \\
0.009]\end{array}$ & $\begin{array}{c}{[-0.016} \\
0.003]\end{array}$ & $\begin{array}{c}{[-0.009} \\
0.013]\end{array}$ & $\begin{array}{c}{[-0.001} \\
0.030]\end{array}$ & $\begin{array}{c}{[-0.019} \\
0.005]\end{array}$ \\
\hline $\begin{array}{l}\text { 95\% Confidence Band, } \\
\text { scaled by mean screening } \\
\text { rate }\end{array}$ & $\begin{array}{c}{[-0.021} \\
0.011]\end{array}$ & $\begin{array}{c}{[-0.030} \\
0.014]\end{array}$ & $\begin{array}{c}{[-0.040} \\
0.008]\end{array}$ & $\begin{array}{c}{[-0.017} \\
0.025]\end{array}$ & $\begin{array}{c}{[-0.002} \\
0.060]\end{array}$ & $\begin{array}{c}{[-0.032,} \\
0.008]\end{array}$ \\
\hline $\mathrm{N}$ & 1009965 & 1155814 & 843960 & 252232 & 340931 & 1662616 \\
\hline
\end{tabular}

Notes: robust standard errors corrected for within-state correlation in the error term are reported in parentheses. All regressions included state and year fixed effects.

Source: 1987 - 2008 Behavioral Risk Factor Surveillance System Records.

*** Significant at the 1 percent level.

** Significant at the 5 percent level.

* Significant at the 10 percent level. 
TABLE 9. The Relationship between National-Standard Laws and Inpatient

Mortality Rate for Selected Conditions (Logged, Risk-Adjusted)

\begin{tabular}{lccc}
\hline \hline & $(1)$ & $(2)$ & $(3)$ \\
\hline National-Standard (NS) & $-0.076^{* *}$ & $-0.093^{* *}$ & -0.090 \\
Law Dummy & $(0.035)$ & $(0.040)$ & $(0.081)$ \\
NS Law * Below Avg. & $0.128^{*}$ & $0.171^{* *}$ & 0.186 \\
State & $(0.073)$ & $(0.65)$ & $(0.109)^{*}$ \\
$\mathrm{~N}$ & 1104 & 1093 & 1093 \\
\hline Control Variables? & NO & YES & YES \\
State-Specific Linear & NO & NO & YES \\
Trends? & &
\end{tabular}

Notes: robust standard errors corrected for within-state correlation in the error term are reported in parentheses. All regressions include state and year fixed effects and are weighted by the number of admissions (for the relevant state and year) in the sub-sample of discharges associated with the selected conditions (i.e., the sum of discharges for acute myocardial infarction, heart failure, acute stroke, gastrointestinal bleeding, hip fracture or pneumonia). Mortality rates are risk-adjusted for the incidence (among the sub-sample) of each of the conditions comprising the sub-sample of selected conditions.. The regressions also include a separate dummy variable indicating whether the state has an initially below-average inpatient mortality rate (coefficient omitted). Utilization data is from the NHDS.

*** Significant at the 1 percent level.

** Significant at the 5 percent level.

* Significant at the 10 percent level. 
Table 10. The Relationship between National-Standard Laws and Avoidable Hospitalization Rates

(Logged, Normalized by Low-Variation Health Index)

\begin{tabular}{|c|c|c|c|c|c|c|}
\hline & (1) & $(2)$ & (3) & (4) & $(5)$ & $(6)$ \\
\hline & \multicolumn{3}{|c|}{ RATES BASED ON ALL AVOIDABLE } & \multicolumn{3}{|c|}{ RATES BASED ON LOW-DISCRETIONARY } \\
\hline & \multicolumn{3}{|c|}{ HOSPITALIZATIONS } & \multicolumn{3}{|c|}{ AVOIDABLE HOSPITALIZATIONS } \\
\hline National-Standard (NS) & $-0.474 * * *$ & $-0.331 * * *$ & $-0.223 * * *$ & $-0.545^{* * *}$ & $-0.399 * * *$ & $-0.272 * * *$ \\
\hline Law Dummy & $(0.077)$ & $(0.064)$ & $(0.036)$ & $(0.075)$ & $(0.064)$ & $(0.051)$ \\
\hline NS Law * Below Avg. & $0.460 * * *$ & $0.290^{* *}$ & $0.201^{* * *}$ & $0.534 * * *$ & $0.381 * * *$ & $0.247^{* * *}$ \\
\hline State & $(0.130)$ & $(0.113)$ & $(0.046)$ & $(0.126)$ & $(0.113)$ & $(0.071)$ \\
\hline $\mathrm{N}$ & 1139 & 1128 & 1128 & 1139 & 1128 & 1128 \\
\hline \multirow{2}{*}{$\begin{array}{l}\text { Control Variables? } \\
\text { State-Specific Linear } \\
\text { Trends? }\end{array}$} & NO & YES & YES & NO & YES & YES \\
\hline & NO & NO & YES & NO & NO & YES \\
\hline
\end{tabular}

Notes: robust standard errors corrected for within-state correlation in the error term are reported in parentheses. All regressions include state and year fixed effects and are weighted by the low-variation health index (i.e., the sum of discharges for acute myocardial infarction, stroke, hip fracture or gastrointestinal bleeding) associated with each state-year cell. The regressions also include a separate dummy variable indicating whether the state has an initially below-average avoidable hospitalization rate or low-discretionary avoidable hospitalization rate, as appropriate (coefficient omitted). Utilization data is from the NHDS.

*** Significant at the 1 percent level.

** Significant at the 5 percent level.

* Significant at the 10 percent level. 
Table 11. The Relationship between National-Standard Laws and

The Rate of Maternal Trauma among Deliveries (Logged)

\begin{tabular}{lccc}
\hline \hline & $(1)$ & $(2)$ & $(3)$ \\
\hline National-Standard (NS) & -0.126 & -0.195 & $-0.286^{* * *}$ \\
$\quad$ Law Dummy & $(0.190)$ & $(0.124)$ & $(0.082)$ \\
NS Law * Below Avg. & 0.083 & 0.058 & 0.224 \\
State & $(0.229)$ & $(0.177)$ & $(0.215)$ \\
$\mathrm{N}$ & 1089 & 1076 & 1076 \\
\hline Control Variables? & NO & YES & YES \\
State-Specific Linear & NO & NO & YES \\
Trends?
\end{tabular}

Notes: robust standard errors corrected for within-state correlation in the error term are reported in parentheses. All regressions include state and year fixed effects and are weighted by the number of deliveries associated with the relevant state-year cell. The regressions also include a separate dummy variable indicating whether the state has an initially below-average trauma rate (coefficient omitted). Utilization data is from the NHDS.

*** Significant at the 1 percent level.

** Significant at the 5 percent level.

* Significant at the 10 percent level. 
Table 12. The Relationship between National-Standard Laws and the

Rate of Preventable Complications During Deliveries (Logged).

\begin{tabular}{|c|c|c|c|}
\hline & (4) & (5) & $(6)$ \\
\hline National-Standard (NS) & $-0.403^{* * *}$ & $-0.445^{* * *}$ & $-0.420 * * *$ \\
\hline Law Dummy & $(0.086)$ & $(0.070)$ & $(0.101)$ \\
\hline NS Law * Below Avg. & $0.513^{* * *}$ & $0.466^{* * *}$ & $0.495 * * *$ \\
\hline State & $(0.135)$ & $(0.103)$ & $(0.175)$ \\
\hline $\mathrm{N}$ & 1089 & 1076 & 1076 \\
\hline Control Variables? & NO & YES & YES \\
\hline $\begin{array}{l}\text { State-Specific Linear } \\
\text { Trends? }\end{array}$ & NO & NO & YES \\
\hline \multicolumn{4}{|c|}{$\begin{array}{l}\text { Notes: robust standard errors corrected for within-state correlation in the } \\
\text { error term are reported in parentheses. All regressions include state and } \\
\text { year fixed effects and are weighted by the number of deliveries } \\
\text { associated with the relevant state-year cell. The regressions also include } \\
\text { a separate dummy variable indicating whether the state has an initially } \\
\text { below-average preventable complication rate (coefficient omitted). } \\
\text { Utilization data is from the NHDS. } \\
\text { *** Significant at the } 1 \text { percent level. } \\
\text { ** Significant at the } 5 \text { percent level. } \\
\text { * Significant at the } 10 \text { percent level. }\end{array}$} \\
\hline
\end{tabular}




\title{
DOES MEDICAL MALPRACTICE LAW IMPROVE HEALTH CARE QUALITY?
}

\author{
By Michael Frakes and Anupam B. Jena
}

\section{Online Appendix A: Conditions under which Probability of Court Error Will Induce Increase in Precaution-Taking Rate.}

Consider a situation as in Figure 2 of the text. The benefits of the precaution perceived by the physician, as a function of $s, B^{*}(s)$, intersects with the costs of the precaution, $C$, at $s^{*}$. Consider a patient with risk characteristics, $s$, just below $s^{*}$. Typically, the physician would perceive the costs of the precaution as being greater than the benefits and elect not to provide the precaution for this patient. However, introduce the possibility that courts will err and expect that physicians indeed provide the precaution to this patient. We assume that physicians will reevaluate their inclinations not to provide the precaution to this patient by comparing the expected level of damages that may ensue from failing to provide the precaution to this patient with the perceived net cost, in the eyes of the physician, associated with providing the patient with this precaution. This latter cost is easily specified. In this range below $s^{*}$, the cost of the precaution exceed the benefits of providing the precaution perceived by the physician by an amount equal to $C-B^{*}(s)$. As long as the expected liability associated with not providing the precaution to this patient is less than this perceived cost of treatment, the physician will continue to avoid providing the precaution in the face of this patient. If expected liability costs exceed these perceived net costs of precaution, the physician will go against their normal instincts and provide the precaution (note that we are simply assuming risk neutrality here). As such, to specify those conditions under which the possibility of court err in ascertaining customary practices will cause physicians to increase their precaution-taking rate, we must determine at what complication level, $s$, the expected liability costs at least equal $C-B^{*}(s)$.

For a given $s$ in the range below $s^{*}$, the expected liability damages associated with not providing the precaution will depend on the distribution of court-determined damages. Even though the true customary perceived benefits of providing the precaution equal $B^{*}(s)$ at this level of $s$, assume, for instance, that a court will err by implicitly assuming that the perceived benefits equal 
$B^{* *}(s)$, a level that now exceeds the costs, $C$, of providing the precaution. If the precaution is not provided, assume that courts will assess a level of damages equal to the forgone benefits associated with the precaution, $B^{* *}(s)$, net of the costs of the precaution-i.e., $B^{* *}(s)-C$. As such, the expected liability costs will equal the expected value of such amounts over the distribution of possible $B^{* *}(s)$ 's (subject to the condition that such damage amounts be greater than zero). For simplicity, assume that each possible $B^{* *}(s)$ is simply a shift upwards of $B^{*}(s)$ by an amount equal to $k$. As such, for a given $s$, the expected liability damages equals:

$$
\int_{k=0}^{\infty} f(k)\left(B^{*}(s+k)-C\right) * I\left(B^{*}(s+k)-C>0\right)
$$

Thus, in the face of uncertainty regarding the courts assessment of where customary standards lie, physicians will increase their precaution-taking rate and thus lower their operable cut-off point below $s^{*}$ until the point at which

$$
C-B^{\prime}(s)=\int_{k=0}^{\infty} f(k)\left(B^{\prime}(s+k)-C\right) * I\left(B^{\prime}(s+k)-C>0\right)
$$




\section{Online Appendix B: Data Sources, Quality Measures, and Covariates}

\section{National Hospital Discharge Survey}

Healthcare quality data is collected from the National Hospital Discharge Survey (NHDS), a nationally-representative sample of inpatient discharge records from short-stay, non-federal hospitals. For approximately 260,000 inpatient records per year, the NHDS contains information on, among other things: (a) primary and secondary diagnosis and procedure codes, (b) certain demographic characteristics of the patient, and (c) certain characteristics of the hospital. We supplement the public NHDS files with geographic identifiers (restricted-use variables) received pursuant to an agreement with the Research Data Center (RDC) at the National Center for Health Statistics (NCHS). All empirical work was performed onsite at the RDC in Hyattsville, Maryland. The resulting sample covers the years 1979 to 2005 . While we also have access to the 1977 and 1978 NHDS records, such records use ICD-8 diagnosis codes (as distinct from the ICD-9-CM codes used thereafter), complicating the ability to form consistent formulations over time of some of the more complicated quality-indicators embraced throughout this analysis.

\section{Healthcare Quality Measures}

For the purposes of this study, we largely look to the AHRQ for guidance in selecting quality metrics. The AHRQ measures are particularly useful for the present study in so far as they are designed for use with administrative inpatient databases such as the NHDS. The AHRQ's quality indicators are essentially classified into 3 modules: (1) Prevention Quality Indicators (PQIs), identifying admissions that could have been avoided through access to high-quality outpatient care, (2) Inpatient Quality Indicators (IQIs), reflecting the quality of care inside hospitals including inpatient mortality for certain medical conditions, and (3) Patient Safety Indicators (PSIs), focusing on potentially avoidable complications during inpatient care.

For the purposes of this analysis, we attempt to construct quality metrics that are meant to cover each of these three domains.

Avoidable hospitalizations. First, we calculate a rate of avoidable hospitalizations (AH) within each state-year cell, a measure inspired by the AHRQ's PQIs. AH rates, generally, and the PQIs, specifically, are measures that are constructed using inpatient data, though meant to reflect the quality of care prevailing in the associated outpatient / ambulatory community. Such measures identify conditions (e.g., asthma, diabetes, malignant hypertension, etc.) with respect to which proper outpatient care would have prevented the need for hospitalization. According to the AHRQ, their PQIs grew out of research in the early 1990s by Joel Weissman and colleagues. ${ }^{1}$ The Weissman et al. (1992) AH classification scheme is designed in slightly more general terms

\footnotetext{
${ }^{1}$ See http://www.qualityindicators.ahrq.gov/Downloads/Modules/PQI/PQI\%20Summary\%20Report.pdf.
} 
than the PQIs and thus arguably lends itself to easier codification using a set of NHDS records that span several decades (considering the complexity associated with tracking variations in ICD classifications over time). ${ }^{2}$ For this reason, and in light of the fact that Weismann et al. developed their classification during the middle of the period in which the NCHS sampled physicians to compile the NHDS (unlike the PQIs, which came later), we elect to construct an $\mathrm{AH}$ rate for this analysis using the Weissman et al. classification.

To calculate avoidable hospitalization rates for each state and year in the sample, we first count the number of hospitalizations within the NHDS records for that state-year cell in which a diagnosis is indicated for any of the conditions included in the Weissman et al. (1992) classification. We perform such counts under two alternative approaches: one in which the conditions are identified in any one of the indicated diagnosis codes and one in which the conditions are identified in the primary diagnosis code only (the preferred approach that we take). To form the relevant rate, it is of course necessary to normalize these AH counts in some manner. Following Frakes (2013), we elect to use measures internal to the NHDS records to form the relevant denominator for each state-year AH rate, taking several alternative approaches to this normalization. ${ }^{3}$ In one approach, for example, we normalize each AH count by the number of hospitalizations associated with the delivery of a child found in the NHDS records for the relevant state and year. This approach allows for a scaling of the AH count by a measure reflective of the size of the associated state-year sample, while also offering a denominator that is itself not likely to be significantly impacted by the prevailing malpractice environment (allowing for a focus on the influence of malpractice on the AH count comprising the numerator, our margin of interest).

Primarily, however, based on the same premise as the delivery approach and following Frakes (2013), we normalize each state-year AH count by an index of hospitalizations equal to the count of admissions associated with any of the following conditions and events: (1) acute myocardial infarction, (2) stroke, (3) gastro-intestinal bleeding or (4) hip fracture. Such events represent situations characterized by relatively little variation across regions (see, for example, Wennberg 1984 and Wennberg and Cooper 1999), even in the face of environments that impose varying legal and financial incentives (i.e., where such hospitalizations are better seen as proxies for the underlying disease environment, as opposed to reflections of immediate healthcare utilization

\footnotetext{
${ }^{2}$ Those conditions represented in the Weissman et al. (1992) classification include: ruptured appendix, asthma, cellulitis, congestive heart failure, diabetes, gangrene, hypokalemia, immunizable conditions, malignant hypertension, pneumonia, pyelonephritis, and perforated or bleeding ulcer.

${ }^{3}$ The NHDS weights are not designed to generate representative state-specific estimates. Of course, observing within-state changes over time in the set of records included in the state-year cells nonetheless affords the ability to identify the intended relationships (Dafny and Gruber 2005). In any event, though noisier, the results of this exercise generally persist under alternative approaches that either (1) multiply observations by the NHDS sample weights and form $\mathrm{AH}$ rates by dividing weighted $\mathrm{AH}$ counts by the total population of that state (yet another normalization approach), or (2) forming dependent variables based on the natural log of the state-year AH counts (i.e., under no normalization at all). The primary approaches taken, however, soften some of the sampling variability that occurs within states over time, while normalizing by a measure that is more directly reflective of the scale of the hospital sampled.
} 
decisions). As such, this index likewise affords an appropriate scaling of the numerator count with arguably little concern over the malpractice environment impacting the scaling metric. ${ }^{4}$ In yet another alternative approach, we simply normalize by the count of acute myocardial infarction discharges (primary diagnosis only) for the relevant state and year.

Low-discretionary avoidable hospitalizations. As an alternative AH rate, we focus on those subset of avoidable hospitalizations over which physicians have less discretion in admitting patients. Use of this alternative measure will ease concerns that fluctuations in the liability regime will capture changes not just in outpatient quality but in inpatient admission decisions. Following Weismann et al. (1991), Wennberg (1988) and Twigger and Jessop (2000) for guidance, we select the following conditions out of the Weissman et al. (1992) conditions as being on the lower end of the discretionary scale: ruptured appendix, pneumonia, and congestive heart failure.

Inpatient mortality for selected conditions. Following the AHRQ's IQIs, we next construct a quality measure in which we calculate the composite rate of inpatient mortality among a subsample of discharges in which the primary diagnosis code indicates any one of the following conditions: acute myocardial infarction, heart failure, acute stroke, gastrointestinal bleeding, hip fracture or pneumonia. Such events are generally high volume in occurrence, allowing for robust sample sizes. It is worth noting that such conditions, for the most part, also represent lowdiscretionary hospitalizations, whereby inpatient admissions generally follow upon their occurrence. ${ }^{5}$ With this in mind, mortality rates among this sub-sample of admissions can be seen as more likely reflective of the quality of care observed during the inpatient stay itself, rather than as a result of risk selection by providers or patients.

Of course, a concern arises regarding fluctuations in the proportions of the various conditions comprising this selected-conditions sub-sample. That is, a reduction in the composite mortality rate could arise from a relative increase in the rate of hip fracture admissions (where mortality rates are lower for such admissions relative to the other selected conditions), as opposed to reductions in mortalities that would actually be attributable to improvements in quality. We take two approaches to dealing with this concern. First, in some specifications, we include state-year controls for the proportion of this sub-sample made up of each of the respective conditions. In the primary approach, however, we follow the AHRQ and standardize the composite mortality rate for state-year changes in the various incidences of the conditions.

To risk adjust mortality rates, we employ an indirect standardization approach, in which we first predict the mortality rate that a national sample of patients would be expected to experience if

\footnotetext{
${ }^{4}$ See Frakes (2013) for empirical support over the contention that the incidences of these low-variation conditions are not sensitive to medical liability standards. Note that higher quality outpatient care may be effective at reducing some amount of hospitalizations for the above-indicated low-variation conditions, though likely to an extent less than quality care may reduce the incidence of the Weissman et al. (1992) avoidable conditions, in which case the proposed avoidable hospitalization rate nonetheless identifies a relative quality measure.

${ }^{5}$ For a discussion of the selection of low-discretionary hospitalization categories, see Carter (2003).
} 
they faced the relevant patient characteristics of each state-year cell. We generate such predictions based on the estimated coefficients from national, annual regressions of mortality incidence on the incidence of the relevant set of conditions. We then calculate the standardized mortality rate by (1) taking the ratio between the observed state-year composite mortality rate and this predicted national mortality rate and (2) multiplying this ratio by the observed national mortality rate.

Patient safety incidents and delivery complications. For the reasons set forth in the text, we focus our patient-safety analysis on the delivery-related PSI's inspired by the AHRQ, which represent third and fourth degree lacerations during deliveries (aggregating this analysis across vaginal and cesarean deliveries). Again following Currie and MacLeod (2008), we supplement these PSI delivery measures by forming a measure equal to the incidence of preventable delivery complications: fetal distress, excessive bleeding, precipitous labor, prolonged labor, or dysfunctional labor.

\section{Behavioral Risk Factor Surveillance System}

Our data source for the cancer-screening analysis is the Behavioral Risk Factor Surveillance System (BRFSS). The data consists of repeated cross-sections for the years 1987 through 2008, collected via monthly telephone surveys of individuals aged 18 years and older. The BRFSS is a nationally representative survey of the United States and has been conducted by state health departments in coordination with the CDC for the purpose of collecting state-level data pertaining to certain personal health behaviors. Fifteen states took part in the first survey in 1984 . By 1994, all 50 states and the District of Columbia became involved. The survey was administered to an average of 817 individuals per state in 1984, rising to an average of nearly 8000 per state in 2008.

\section{Cancer-Screening Measures}

Sigmoidoscopy / Colonoscopy. In our primary specification, we aimed to construct a proctoscopy screening measure in line with recommended screening guidelines. As such, we focused on the age group between 50 and 75 years old and created an indicator variable equal to “ 1 ” if the respondent has had a sigmoidoscopy or a colonoscopy within the last 5 years. In alternative specifications we simply indicate whether or not the respondent within this age range has ever had a sigmoidoscopy or a colonoscopy. Proctoscopic examination information within the BRFSS is available from 1988 onwards.

Mammogram. In our primary specification, we construct a mammogram screening measure in line with the recommended screening guidelines in place for most of our sample period. Accordingly, limiting our sample to those female respondents with an age between 40 and 75 year olds, we created an indicator variable reflecting whether or not the respondent received a mammogram within the last 2 years. In alternative specifications, we simply indicate whether or 
not the respondent within this age range has ever had a mammogram. Mammography information within the BRFSS is available from 1987 onwards.

Physical breast exam. Likewise in line with recommended guidelines, our primary specifications construct physical or clinical breast exam utilization measures by looking at the sample of at least 40 years of age and asking whether or not they have had a break exam within the last year. In alternative specifications, we simply indicate whether or not they have ever had a physical breast exam. Physical breast exam information within the BRFSS is available from 1990 onwards.

PSA Testing. Consistent with recommendations, at least with respect to those recommendations operating over our sample period, we focus on the sample of males over the age of 50 (and under the age of 75) and construct an indicator regarding whether or not they have received ProstateSpecific Antigen (PSA) Testing within the last year. In alternative specifications, we simply indicate whether or not they have ever had PSA testing. PSA testing information within the BRFSS is available from 2001 onwards.

Digital Rectal Exam. Consistent with recommendations, at least with respect to those recommendations operating over our sample period, we focus on the sample of males over the age of 50 (and under the age of 75) and construct an indicator regarding whether or not they have received a Digital Rectal Exam (DRE) within the last year. In alternative specifications, we simply indicate whether or not they have ever had a DRE. DRE information within the BRFSS is available from 1988 onwards, though not at sufficient numbers until 1993 onwards (with several years omitted in the late 1990s).

Pap smear. Consistent with recommendations, at least with respect to those recommendations operating over our sample period, we focus on the sample of females 21 years old and over and construct an indicator regarding whether or not they have received pap testing within the last year. In alternative specifications, we simply indicate whether or not they have ever had a pap smear. Pap testing information within the BRFSS is available from 1987 onwards.

\section{Other Tort Reforms}

A number of specifications include the incidence of additional tort measures as covariates, including reforms of the collateral source rule, caps on punitive-damages awards and other “indirect” tort reforms. Traditional collateral source rules generally prohibited defendants from introducing evidence of compensatory payments made to plaintiffs from outside sources (e.g., insurers). Thirty-three states currently have laws in place that eliminate this traditional rule, effectively reducing the scope of compensatory damage awards. Much of these reforms likewise occurred during the mid-1980s; however, there are a substantial amount of independent reforms of each type, facilitating identification of their separate impacts. 
Punitive damages are awarded on a much rarer basis in malpractice actions than are noneconomic damages awards (without a correspondingly large increase in average payouts). ${ }^{6}$ Thus, relative to non-economic damages, it is arguable that the threat of liability for punitive damages will have a weaker impact on physician behavior. Nonetheless, despite the infrequent application of such awards, considering that punitive damages are generally not insured by liability carriers, it remains reasonable to believe that physicians may be sensitive to the threat posed by punitive awards (Malani and Reif 2012). Finally, following the classification of malpractice reforms introduced by Kessler and McClellan (1996), we estimate the general impact associated with a residual reform category (labeled "indirect” reforms) that includes contingency fee limitations, requirements of periodic payment of future damages, joint and several liability reforms, and provisions for a patients' compensation fund. ${ }^{7}$

\section{Other Covariates (by Quality Indicator)}

Inpatient mortality rate for selected medical conditions. In the case of the mortality rates specifications, estimated according to equation (1) in the text, $\mathbf{X}_{\mathbf{s}, \mathbf{t}}$ represents certain demographic characteristics: the percentage of patients in various age-sex categories, ${ }^{8}$ race categories (white, black and other), insurance categories (private, government, no insurance and other), along with the percentage of patients visiting hospitals of various bed sizes $(0-100,100$ 200, 200-300, 300-500 and 500+ beds) and of various ownership types (proprietary, non-profit and government). ${ }^{9} \quad \mathbf{Z}_{\mathbf{s}, \mathbf{t}}$ represents certain other state-year characteristics (HMO penetration rate and its square, physician concentration rate, and median household income). ${ }^{10}$

\footnotetext{
${ }^{6}$ For evidence of this claim, see Cohen (2005) and Hyman et al. (2009).

${ }^{7}$ The results presented below for the damage caps and collateral source rule reform coefficients are entirely robust to inclusion of a richer set of controls for each of the individual components of Kessler and McClellan's indirect reform category.

${ }^{8}$ Age-sex categories for the inpatient mortality and AH specifications are as follows: male under 30 , female under 30, male 30-45, female 30-45, male 45-55, female 45-55, male 55-65, female 55-65, male 65-75, female 65-75, male over 75 and female over 75 . Age-sex categories for the obstetric specifications are as follows: 15-19, 20-24, 25-29, 30-34, 35-39 and 40+ years old.

${ }_{9}$ We form the incidences of the relevant demographic variables using the NHDS sample itself, though the results are entirely robust to alternative state-year controls based off of the Census data. Following Frakes (2013), in the $\mathrm{AH}$ rate and mortality rate specifications, we form the relevant incidences using the sample of discharges in which patients present themselves for acute myocardial infarction, stroke, gastro-intestinal bleeding or hip fracture. This subsample consists of patients that will almost universally seek hospitalization upon the occurrence of the event, in which case the sample itself is generally not sensitive to the prevailing legal environment. In any event, the results of this exercise are also robust to the formation of the demographic covariates using the entire sample of state-year NHDS discharges. In the obstetrics specifications, we form all relevant incidences using the subsample of discharges associated with deliveries.

${ }^{10}$ HMO penetration rates are from Interstudy Publications. Household income data is from the decennial Census files and the American Community Surveys. Data on physician population counts are from the American Medical Association (AMA) administrative records and were obtained from the Area Resource File.
} 
In alternative specifications, we also control for the average length of stay associated with hospitalizations for such medical conditions. To the extent that medical liability forces also impact lengths of stay for such hospitalizations, any such development could confound the estimation of liability forces on inpatient mortality rates insofar as longer hospitalizations otherwise increase the probability of an inpatient mortality. The results are virtually unchanged with such controls. Supporting this insensitivity to the inclusion of length-of-stay controls, we also find, in separate specifications (available upon request), no association between the adoption of the various reforms and the length of stay associated with hospitalizations for the selected medical conditions.

Avoidable hospitalization rates. $\mathbf{X}_{\mathrm{s}, \mathrm{t}}$ and $\mathbf{Z}_{\mathrm{s}, \mathrm{t}}$ in the $\mathrm{AH}$ rate specifications are identical to those of the inpatient mortality rate specifications.

Maternal trauma rates and delivery complication rates. In the obstetrics specifications, $\mathbf{X}$ includes mother's age (15-19, 20-24, 25-29, 30-34, 35-39 and 40+ years old); mother's race (white, black and other); mother's insurance status (private, government, no insurance and other); hospital bed size (0-100, 100-200, 200-300, 300-500 and 500+ beds); and hospital ownership type (proprietary, non-profit and government). $\mathbf{Z}_{\mathrm{s}, \mathrm{t}}$ includes the state-year fertility rate, the state-year OB-GYN concentration rate, ${ }^{11}$ the HMO penetration rate (and its square), and median household income. Obstetric specifications also include controls for cesarean delivery and episiotomy utilization. The maternal trauma specifications also include a control capturing the risk-status associated with the delivery, specified following Frakes (2013) as the predicted probability of cesarean delivery (PPC). PPC values are calculated using fitted values of a logit model (estimated annually) of the incidence of cesarean delivery on a set of individual risk factors and complications. We include this measure from Frakes (2013) simply as a way to capture all such risk factors and complications in a single measure. The results are robust to including separate indicator variables for all such measures. Note that we exclude this control in the main specification of the delivery complications specification given that the outcome variable in that context is meant to capture certain of those complications itself. In alternative specifications of the delivery complications approach, we also include controls for all nonpreventable complications and risk factors. The results are virtually identical under such alternative specifications (available upon request).

Cancer Screening Rates. $\mathbf{X}$ in the cancer screening specifications includes various individual characteristics provided for in the BRFSS files: marital status (married, widowed, divorced, single), race (white, black, and other), educational attainment category, Hispanic origin, income (and its square), age category (by age deciles), and smoking status. $\mathbf{Z}$ includes certain characteristics of the prevailing state-year health care market (including physician concentration

\footnotetext{
${ }^{11}$ Fertility rates are calculated according to Gruber and Owings (1996) as the number of births per population and come from the Vital Statistics Natality files (also obtained via the ARF).
} 
rate and the average number of hospital beds per capita), ${ }^{12}$ along with HMO penetration rates and its square.

${ }^{1212}$ Average hospital bed data was likewise obtained from the ARF. 


\section{Online Appendix C: Additional Robustness Checks}

\section{Dynamic Difference-in-Difference Results}

Table C1. Relationship between Damage Caps and the AHRQ-Inspired Quality Indicators: Dynamic

Difference-in-Difference Regression Results

\begin{tabular}{|c|c|c|c|c|c|}
\hline & $(1)$ & $(2)$ & (3) & (4) & (5) \\
\hline \multirow{2}{*}{\multicolumn{6}{|c|}{$\begin{array}{c}\text { PREVENTABLE } \\
\text { DELIVERY } \\
\text { COMPLICA- } \\
\text { TIONS }\end{array}$}} \\
\hline & & & & & \\
\hline Cap & & & & & \\
\hline 4-Year Lead Dummy & $\begin{array}{c}-0.084^{* * *} \\
(0.030)\end{array}$ & $\begin{array}{c}0.023 \\
(0.032)\end{array}$ & $\begin{array}{l}0.037 \\
(0.027)\end{array}$ & $\begin{array}{c}0.003 \\
(0.003)\end{array}$ & $\begin{array}{l}-0.013 \\
(0.010)\end{array}$ \\
\hline 3-Year Lead Dummy & $\begin{array}{l}-0.012 \\
(0.034)\end{array}$ & $\begin{array}{l}-0.030 \\
(0.020)\end{array}$ & $\begin{array}{l}-0.028 \\
(0.023)\end{array}$ & $\begin{array}{l}-0.002 \\
(0.002)\end{array}$ & $\begin{array}{l}0.010 \\
(0.006)\end{array}$ \\
\hline 2-Year Lead Dummy & $\begin{array}{l}-0.010 \\
(0.056)\end{array}$ & $\begin{array}{l}-0.001 \\
(0.027)\end{array}$ & $\begin{array}{l}-0.006 \\
(0.031)\end{array}$ & $\begin{array}{c}0.001 \\
(0.003)\end{array}$ & $\begin{array}{c}0.014 \\
(0.010)\end{array}$ \\
\hline 1-Year Lead Dummy & $\begin{array}{c}0.027 \\
(0.041)\end{array}$ & $\begin{array}{l}-0.008 \\
(0.017)\end{array}$ & $\begin{array}{l}-0.008 \\
(0.024)\end{array}$ & $\begin{array}{l}-0.000 \\
(0.002)\end{array}$ & $\begin{array}{l}-0.007 \\
(0.006)\end{array}$ \\
\hline Contemporaneous & -0.046 & 0.009 & 0.007 & 0.001 & 0.004 \\
\hline Dummy & $(0.048)$ & $(0.028)$ & $(0.031)$ & $(0.003)$ & $(0.005)$ \\
\hline 1-Year Lag Dummy & $\begin{array}{c}0.031 \\
(0.066)\end{array}$ & $\begin{array}{c}0.015 \\
(0.031)\end{array}$ & $\begin{array}{l}-0.004 \\
(0.023)\end{array}$ & $\begin{array}{l}-0.005 \\
(0.005)\end{array}$ & $\begin{array}{c}0.005 \\
(0.010)\end{array}$ \\
\hline 2-Year Lag Dummy & $\begin{array}{c}0.034 \\
(0.067)\end{array}$ & $\begin{array}{c}-0.065^{* *} \\
(0.025)\end{array}$ & $\begin{array}{c}-0.063^{* *} \\
(0.025)\end{array}$ & $\begin{array}{l}-0.003 \\
(0.004)\end{array}$ & $\begin{array}{l}-0.012 \\
(0.011)\end{array}$ \\
\hline 3-Year Lag Dummy & $\begin{array}{c}0.033 \\
(0.054)\end{array}$ & $\begin{array}{c}0.038 \\
(0.027)\end{array}$ & $\begin{array}{c}0.042 \\
(0.027)\end{array}$ & $\begin{array}{c}0.007 \\
(0.005)\end{array}$ & $\begin{array}{c}0.004 \\
(0.011)\end{array}$ \\
\hline 4-Year Lag Dummy & $\begin{array}{l}-0.041 \\
(0.049)\end{array}$ & $\begin{array}{c}0.022 \\
(0.022)\end{array}$ & $\begin{array}{l}-0.002 \\
(0.020)\end{array}$ & $\begin{array}{l}-0.002 \\
(0.003)\end{array}$ & $\begin{array}{l}-0.002 \\
(0.006)\end{array}$ \\
\hline
\end{tabular}

Notes: robust standard errors corrected for within-state correlation in the error term are reported in parentheses. Each specification controls for state fixed effects, year fixed effects, various covariates and a set of state specific linear time trends. Specifications are weighted per their counterparts in Tables 4-7 of the text and otherwise track the specifications in such tables. Dependent variables in Columns $1-3$ (representing state-year means of the respective measures) are logged. Dependent variables in Columns 4 and 5 represent the individual incidence of the respective measure.

*** Significant at the 1 percent level.

** Significant at the 5 percent level.

* Significant at the 10 percent level. 
Table C2. Relationship between Damage Caps and Cancer Screening Rates: Dynamic

Difference-in-Difference Regression Results

\begin{tabular}{|c|c|c|c|c|c|c|}
\hline & (1) & (2) & (3) & (4) & (5) & (6) \\
\hline$\underline{\text { Non-Economic Damage }}$ & $\begin{array}{l}\text { MAMMO- } \\
\text { GRAM }\end{array}$ & $\begin{array}{c}\text { PHYSICAL } \\
\text { BREAST EXAM }\end{array}$ & $\begin{array}{c}\text { PROCTO- } \\
\text { SCOPIC EXAM }\end{array}$ & PSA TESTING & $\begin{array}{c}\text { DIGITAL } \\
\text { RECTAL EXAM }\end{array}$ & PAP SMEAR \\
\hline Cap & & & & & & \\
\hline 4-Year Lead Dummy & $\begin{array}{l}-0.009 \\
(0.006)\end{array}$ & $\begin{array}{l}-0.006 \\
(0.006)\end{array}$ & $\begin{array}{c}-0.019 * * * \\
(0.007)\end{array}$ & $\begin{array}{c}0.013 \\
(0.015)\end{array}$ & $\begin{array}{c}0.007 \\
(0.017)\end{array}$ & $\begin{array}{l}-0.003 \\
(0.006)\end{array}$ \\
\hline 3-Year Lead Dummy & $\begin{array}{c}0.007 \\
(0.004)\end{array}$ & $\begin{array}{c}0.010 \\
(0.008)\end{array}$ & $\begin{array}{l}-0.004 \\
(0.007)\end{array}$ & $\begin{array}{l}-0.023 \\
(0.016)\end{array}$ & $\begin{array}{l}-0.009 \\
(0.015)\end{array}$ & $\begin{array}{l}0.015^{*} \\
(0.007)\end{array}$ \\
\hline 2-Year Lead Dummy & $\begin{array}{c}0.005 \\
(0.006)\end{array}$ & $\begin{array}{l}-0.001 \\
(0.008)\end{array}$ & $\begin{array}{l}-0.002 \\
(0.007)\end{array}$ & $\begin{array}{l}0.022 * \\
(0.011)\end{array}$ & $\begin{array}{c}0.018 \\
(0.012)\end{array}$ & $\begin{array}{l}-0.002 \\
(0.007)\end{array}$ \\
\hline 1-Year Lead Dummy & $\begin{array}{c}0.017^{* *} \\
(0.007)\end{array}$ & $\begin{array}{c}0.032 * * * \\
(0.007)\end{array}$ & $\begin{array}{l}-0.001 \\
(0.011)\end{array}$ & $\begin{array}{c}0.024 * * * \\
(0.009)\end{array}$ & $\begin{array}{l}-0.006 \\
(0.014)\end{array}$ & $\begin{array}{c}0.025 * * * \\
(0.006)\end{array}$ \\
\hline Contemporaneous & $-0.023 * * *$ & $-0.019 * *$ & -0.022 & 0.017 & 0.027 & $-0.018 * * *$ \\
\hline Dummy & $(0.006)$ & $(0.008)$ & $(0.014)$ & $(0.014)$ & $(0.018)$ & $(0.007)$ \\
\hline 1-Year Lag Dummy & $\begin{array}{c}0.019 * * \\
(0.007)\end{array}$ & $\begin{array}{c}0.021 \\
(0.011)\end{array}$ & $\begin{array}{c}0.018 \\
(0.010)\end{array}$ & $\begin{array}{l}-0.008 \\
(0.010)\end{array}$ & $\begin{array}{c}-0.043^{* *} \\
(0.018)\end{array}$ & $\begin{array}{c}0.021 * * \\
(0.010)\end{array}$ \\
\hline 2-Year Lag Dummy & $\begin{array}{c}0.000 \\
(0.006)\end{array}$ & $\begin{array}{c}0.001 \\
(0.009)\end{array}$ & $\begin{array}{l}-0.007 \\
(0.009)\end{array}$ & $\begin{array}{c}0.043^{* *} \\
(0.019)\end{array}$ & $\begin{array}{c}0.032 \\
(0.018)\end{array}$ & $\begin{array}{l}-0.004 \\
(0.010)\end{array}$ \\
\hline 3-Year Lag Dummy & $\begin{array}{c}0.002 \\
(0.008)\end{array}$ & $\begin{array}{l}-0.000 \\
(0.009)\end{array}$ & $\begin{array}{c}0.013 \\
(0.009)\end{array}$ & $\begin{array}{c}0.003 \\
(0.017)\end{array}$ & $\begin{array}{l}-0.017 \\
(0.015)\end{array}$ & $\begin{array}{c}0.014 \\
(0.012)\end{array}$ \\
\hline 4-Year Lag Dummy & $\begin{array}{c}0.002 \\
(0.006)\end{array}$ & $\begin{array}{c}0.001 \\
(0.007)\end{array}$ & $\begin{array}{l}-0.009 \\
(0.008)\end{array}$ & $\begin{array}{c}0.022^{* *} \\
(0.010)\end{array}$ & $\begin{array}{l}-0.009 \\
(0.012)\end{array}$ & $\begin{array}{c}0.005 \\
(0.006)\end{array}$ \\
\hline
\end{tabular}

Notes: robust standard errors corrected for within-state correlation in the error term are reported in parentheses. Each specification controls for state fixed effects, year fixed effects, various covariates and a set of state specific linear time trends.

*** Significant at the 1 percent level.

** Significant at the 5 percent level.

* Significant at the 10 percent level. 
Table C3. Relationship between National Standard Laws and the AHRQ-Inspired Quality Indicators in Initially Low-Quality Areas: Dynamic Difference-in-Difference Regression Results

\begin{tabular}{|c|c|c|c|c|c|}
\hline & $(1)$ & (2) & (3) & (4) & $(5)$ \\
\hline \multirow{2}{*}{\multicolumn{6}{|c|}{$\begin{array}{l}\text { PREVENTABLE } \\
\text { DELIVERY } \\
\text { COMPLICA- } \\
\text { TIONS }\end{array}$}} \\
\hline & & & & & \\
\hline \multicolumn{6}{|l|}{$\underline{\text { Cap }}$} \\
\hline 4-Year Lead Dummy & $\begin{array}{l}-0.041 \\
(0.122)\end{array}$ & $\begin{array}{c}0.075 \\
(0.086)\end{array}$ & $\begin{array}{c}0.101 \\
(0.070)\end{array}$ & $\begin{array}{l}-0.034 \\
(0.171)\end{array}$ & $\begin{array}{c}0.001 \\
(0.132)\end{array}$ \\
\hline 3-Year Lead Dummy & $\begin{array}{l}-0.139 \\
(0.081)\end{array}$ & $\begin{array}{c}0.029 \\
(0.136)\end{array}$ & $\begin{array}{c}0.082 \\
(0.169)\end{array}$ & $\begin{array}{l}-0.143 \\
(0.299)\end{array}$ & $\begin{array}{l}-0.051 \\
(0.081)\end{array}$ \\
\hline 2-Year Lead Dummy & $\begin{array}{c}0.095 \\
(0.091)\end{array}$ & $\begin{array}{l}-0.004 \\
(0.074)\end{array}$ & $\begin{array}{c}0.025 \\
(0.082)\end{array}$ & $\begin{array}{c}0.134 \\
(0.255)\end{array}$ & $\begin{array}{l}-0.135 * \\
(0.067)\end{array}$ \\
\hline 1-Year Lead Dummy & $\begin{array}{c}0.120 \\
(0.134)\end{array}$ & $\begin{array}{l}-0.064 \\
(0.077)\end{array}$ & $\begin{array}{l}-0.116 \\
(0.094)\end{array}$ & $\begin{array}{c}0.193^{* *} \\
(0.076)\end{array}$ & $\begin{array}{c}0.040 \\
(0.154)\end{array}$ \\
\hline Contemporaneous & -0.107 & -0.007 & -0.004 & $-0.470 * *$ & $-0.447 * * *$ \\
\hline Dummy & $(0.074)$ & $(0.089)$ & $(0.083)$ & $(0.207)$ & $(0.137)$ \\
\hline 1-Year Lag Dummy & $\begin{array}{l}-0.032 \\
(0.079)\end{array}$ & $\begin{array}{l}-0.233 \\
(0.139)\end{array}$ & $\begin{array}{l}-0.257 * \\
(0.141)\end{array}$ & $\begin{array}{c}0.048 \\
(0.327)\end{array}$ & $\begin{array}{c}0.283 * * \\
(0.136)\end{array}$ \\
\hline 2-Year Lag Dummy & $\begin{array}{l}-0.077 \\
(0.122)\end{array}$ & $\begin{array}{c}0.049 \\
(0.066)\end{array}$ & $\begin{array}{c}0.027 \\
(0.072)\end{array}$ & $\begin{array}{c}0.141 \\
(0.165)\end{array}$ & $\begin{array}{l}-0.152 \\
(0.092)\end{array}$ \\
\hline 3-Year Lag Dummy & $\begin{array}{c}0.084 \\
(0.153)\end{array}$ & $\begin{array}{l}-0.135 \\
(0.102)\end{array}$ & $\begin{array}{l}-0.138 \\
(0.100)\end{array}$ & $\begin{array}{l}-0.189 \\
(0.180)\end{array}$ & $\begin{array}{c}0.159 \\
(0.147)\end{array}$ \\
\hline 4-Year Lag Dummy & $\begin{array}{l}-0.130 \\
(0.095)\end{array}$ & $\begin{array}{l}-0.165 \\
(0.135)\end{array}$ & $\begin{array}{l}-0.183 \\
(0.137)\end{array}$ & $\begin{array}{l}-0.116 \\
(0.160)\end{array}$ & $\begin{array}{c}0.011 \\
(0.126)\end{array}$ \\
\hline $\begin{array}{l}\text { Notes: robust standarc } \\
\text { specification controls } \\
\text { trends. Specifications } \\
* * * \text { Significant at the } \\
\text { ** Significant at the } 5 \\
\text { * Significant at the } 10\end{array}$ & $\begin{array}{l}\text { corrected for } \\
\text { fixed effect } \\
\text { shted per the } \\
\text { level. } \\
\text { level. } \\
\text { level. }\end{array}$ & $\begin{array}{l}\text {-state cor } \\
\text { fixed effe } \\
\text { erparts in }\end{array}$ & $\begin{array}{l}\text { n the erro } \\
\text { bus covaria } \\
-12 \text { of the }\end{array}$ & $\begin{array}{l}\text { a set of state } \\
\text { ependent vari }\end{array}$ & $\begin{array}{l}\text { entheses. Each } \\
\text { ific linear time } \\
\text { are logged. }\end{array}$ \\
\hline
\end{tabular}


Table C4. Relationship between National Standard Laws and the AHRQ-Inspired Quality Indicators in Initially High-Quality Areas: Dynamic

Difference-in-Difference Regression Results

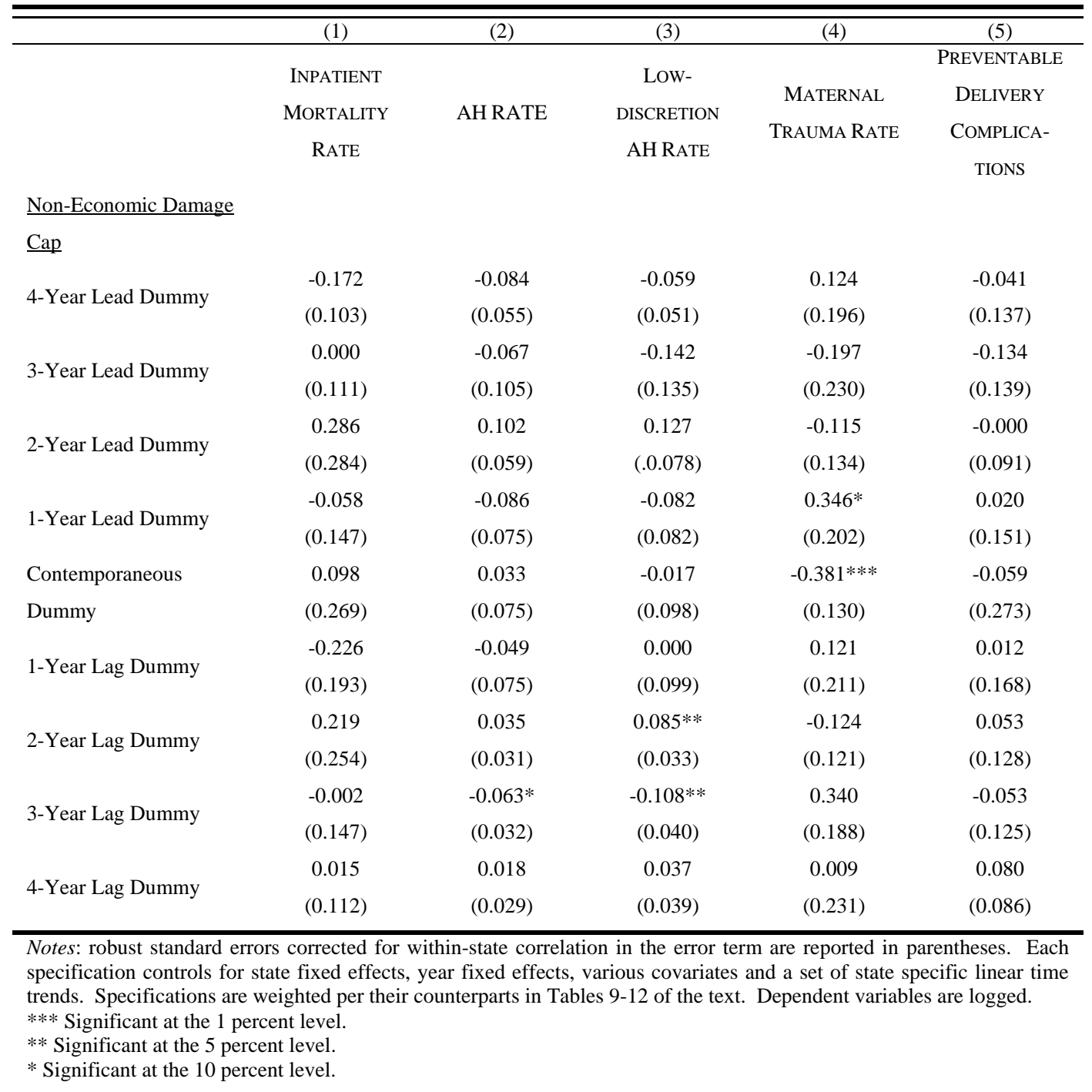

To supplement the above dynamic difference-in-difference tables, we have also produced graphical depictions of the indicated findings. Rather than presenting the full set of findings graphically, however, we only present those bearing on the hypothesis: physicians will respond to standard-of-care reforms that entail the expectation of higher levels of quality by delivering higher quality care. Note that higher levels of care entail lower levels of the AHRQ quality indicators. As such, we expect to observe a decline in such much measures following national standard adoptions in those states that begin with below-average rates and with respect to which the reform entails a heightening of standards. For the reasons indicated below (and in the text), we focus this analysis on the AHRQ-inspired indicators. The figure effectively plots the time trend in the differential quality rate between treatment and control states on a year-by-year basis, where time is measured with reference to years prior to and subsequent to a national standard 
adoption, where this differential is normalized to 0 in the base period (the period of time prior to 4 years before the reform). ${ }^{13}$ The dashed lines in the figures represent the top and bottom of the 95 percent confidence intervals for the respective coefficients.

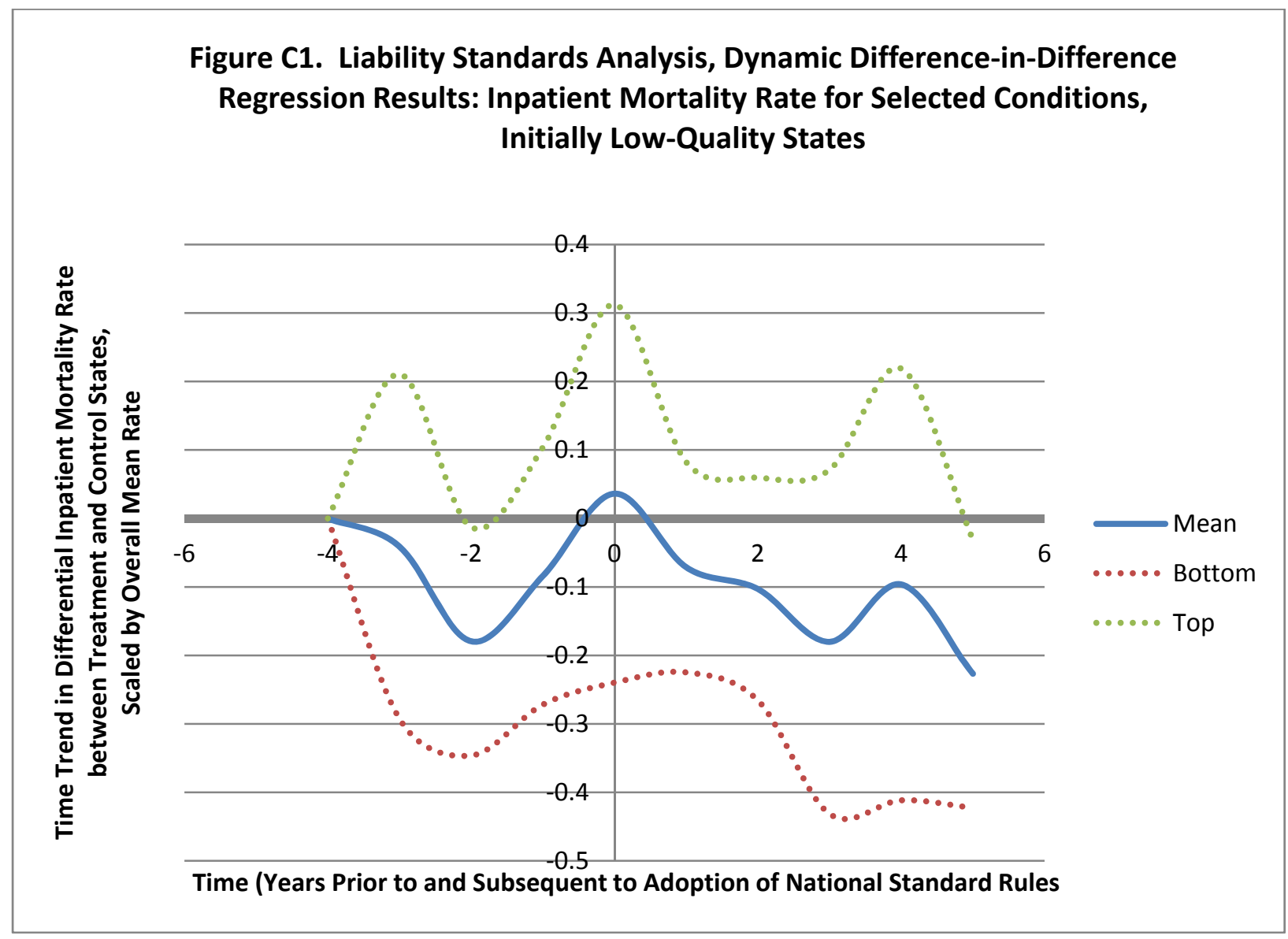

\footnotetext{
${ }^{13}$ In the below figures, time is set such that year " 1 " in the graph represents the time in which the national standard reform is adopted. We do this (rather than setting it at year " 0 ") so that any decline in the indicator (representing an improvement in quality) observed over the first year will manifest itself as a downward slope between year 0 and year 1 in the graph, rather than year -1 and 0 if we were to set the year of reform at year 0 , providing the misleading impression that the decline in the indicator emerged prior to the reform.
} 


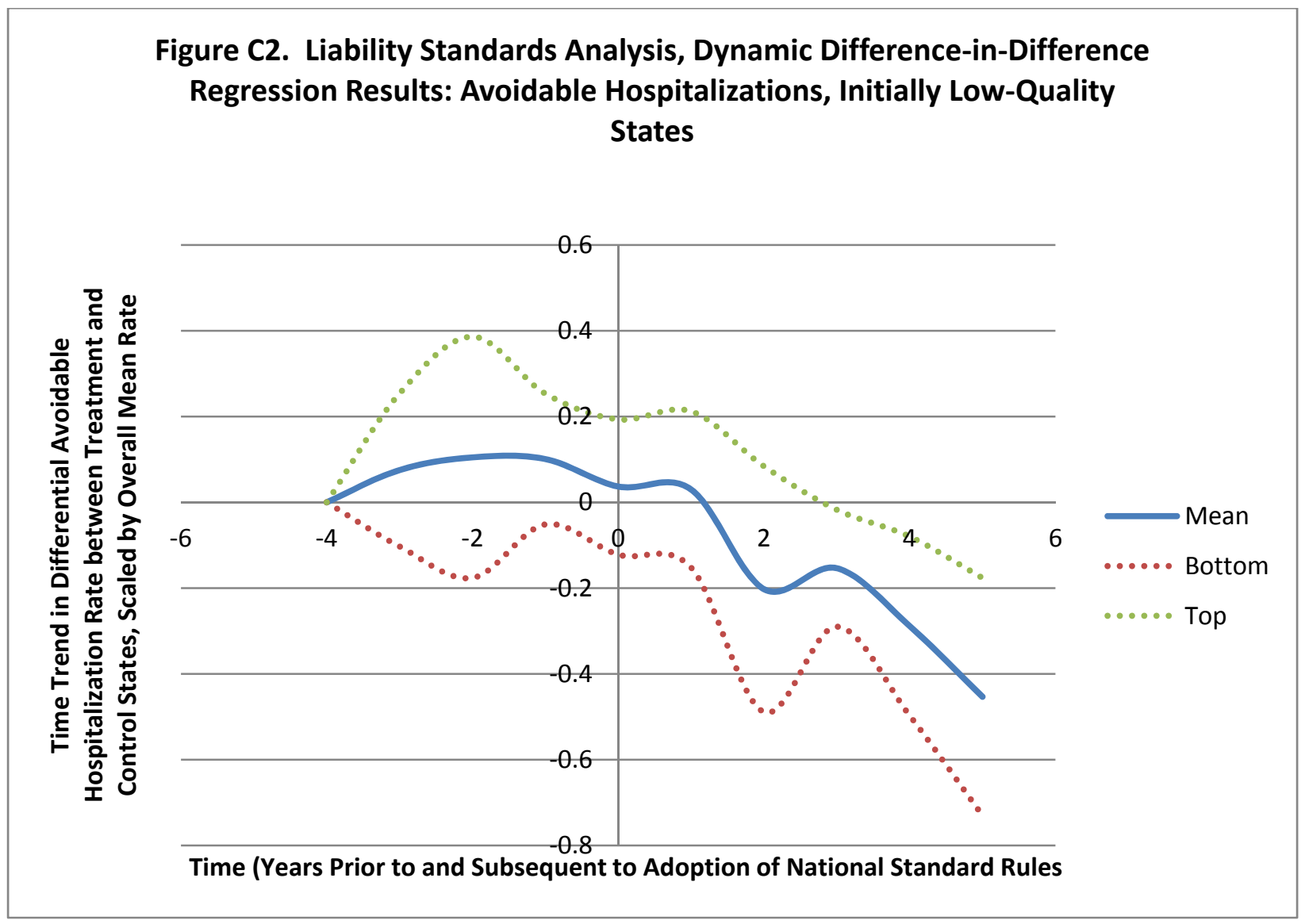




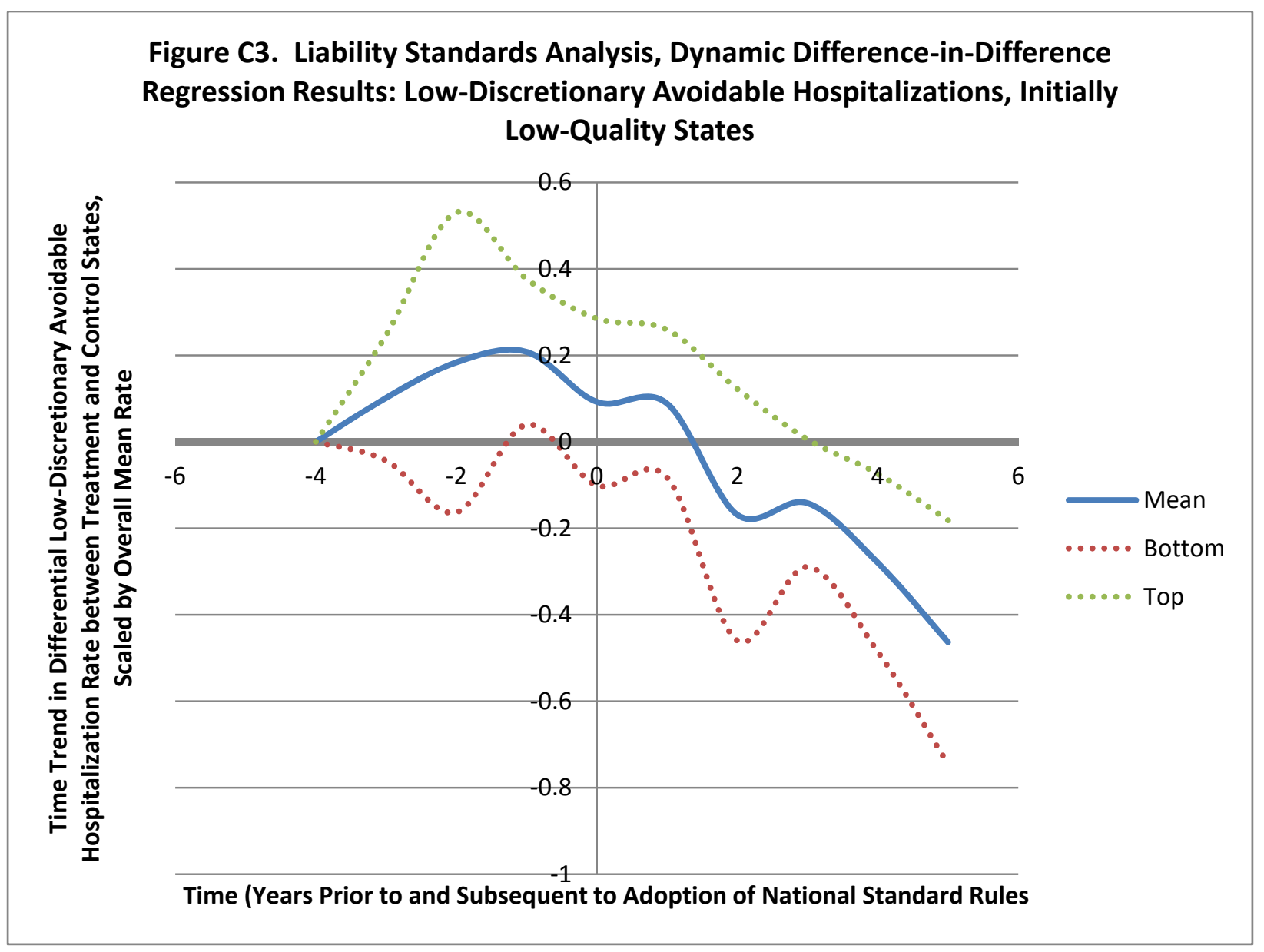




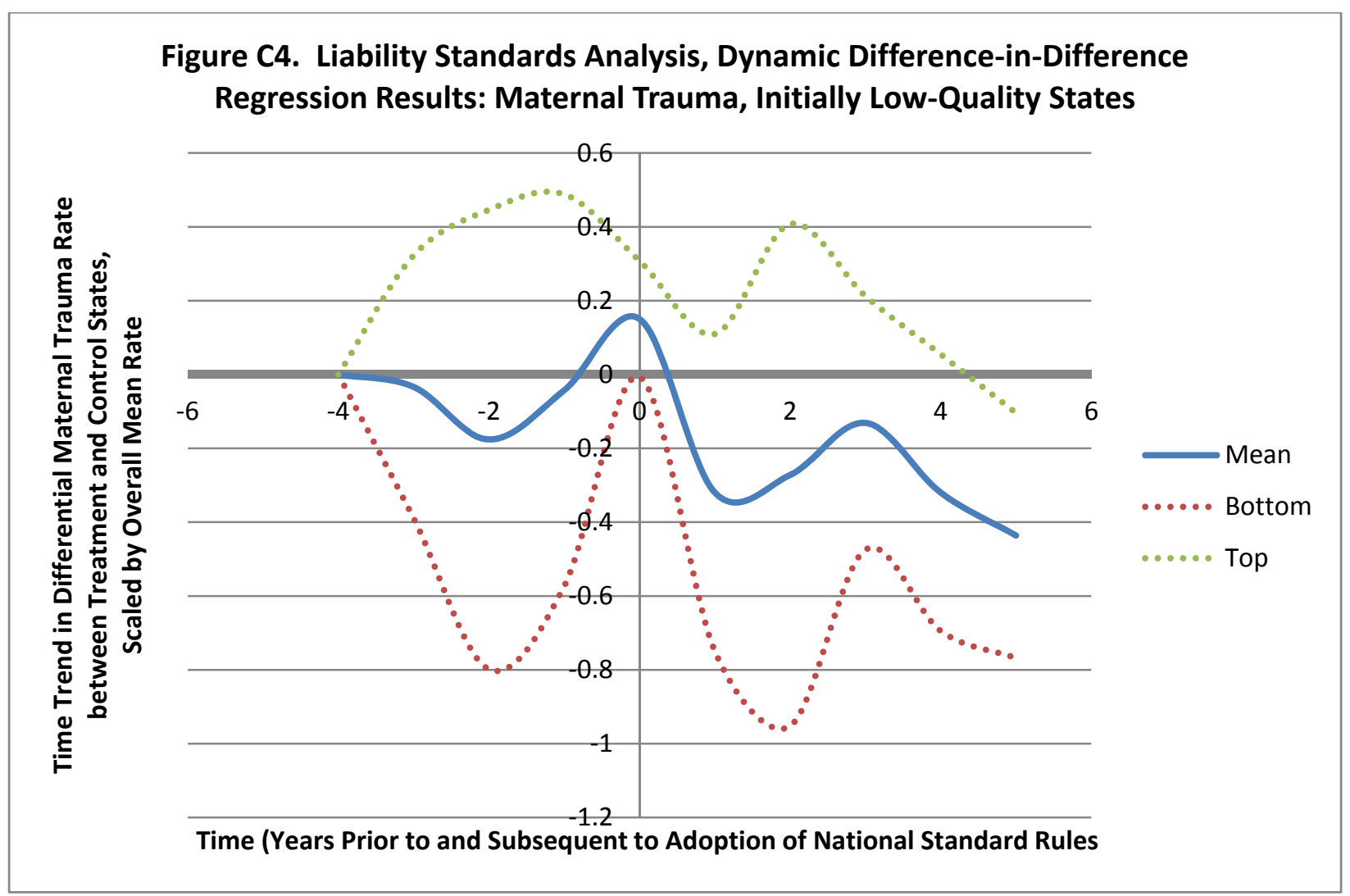




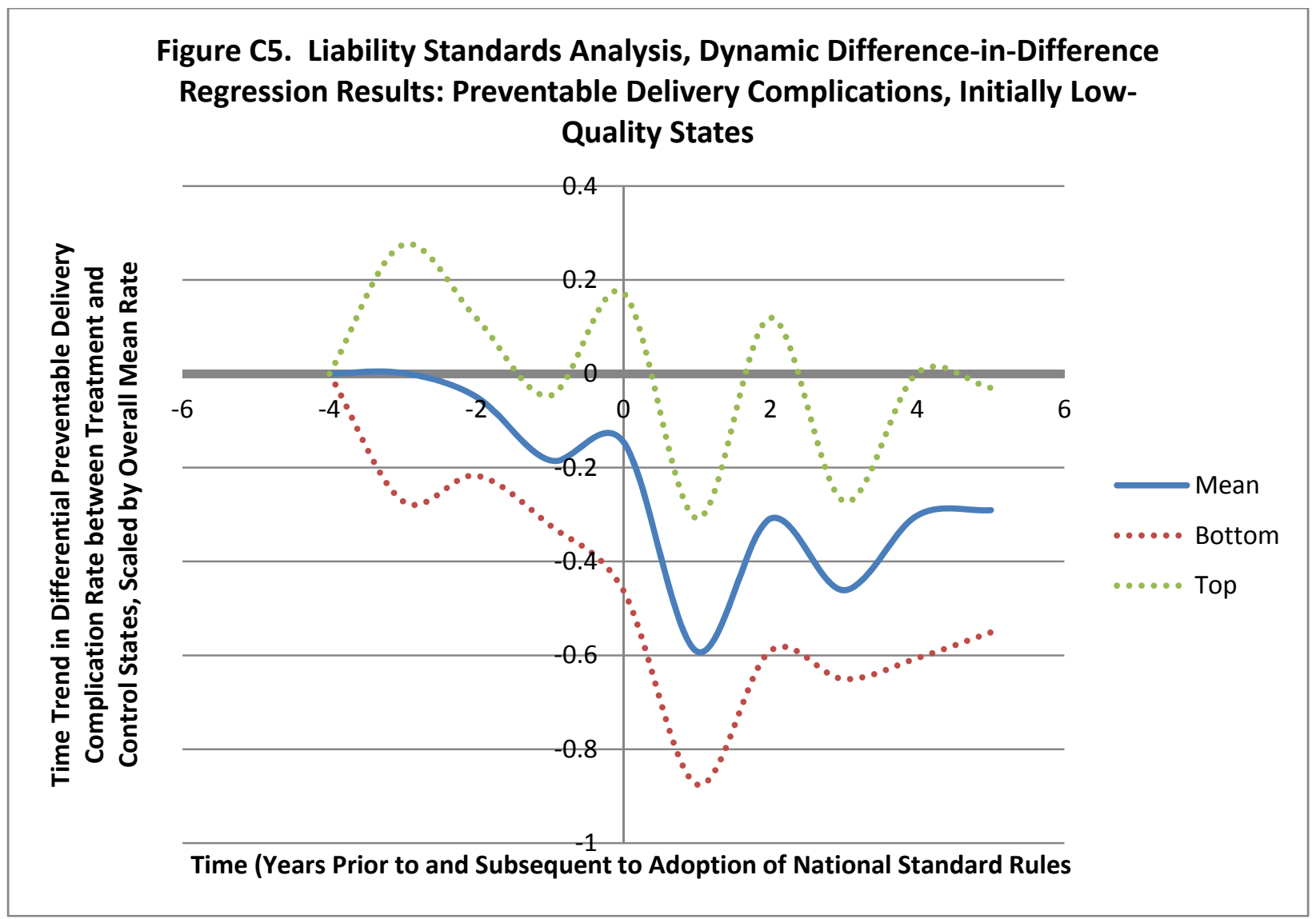

\section{$\underline{\text { Additional Specification Checks }}$}

Construction of Avoidable Hospitalization Rates. The results presented in the text are robust to alternative constructions of the AH Rates, including those constructions that (1) flag avoidable hospitalizations using any diagnosis field, not just the primary diagnosis field, (2) normalize avoidable hospitalization counts by the number of deliveries of children in the associated stateyear cell (an alternative measure of the size of the cell that is not itself subject to influence by the prevailing liability environment), (3) normalize avoidable hospitalization counts by the number of acute myocardial infarctions in the associated state-year cell (rather than the low-variations health index that likewise includes strokes, hip fractures and gastro-intestinal bleedings), (4) use non-logged AH rates as the dependent variable and (5) focus only on the adult (18-plus) population. For instance, when using just acute myocardial infarctions as the denominator in the AH rate, the 95 percent confidence bound for the non-economic damage cap coefficient becomes $[-0.092,0.063]$ as compared with $[-0.068,0.048]$ from Column 3 of Table 5. Similarly, those 
confidence bound becomes [-0.034, 0.058] when using any diagnosis code and [-0.046, 0.058] when focusing only on the adult population. For the purposes of brevity, we avoid setting forth this full set of findings. However, these results are available upon request from the authors.

Construction of Inpatient Mortality Rate for Selected Medical Conditions. The results presented in the text are robust to alternative constructions of the inpatient mortality rate for selected medical conditions, including those constructions that (1) use non-logged mortality rates as the dependent variable, (2) specify the outcome variable as the incidence of mortality out of an individual sample of admissions for the selected medical conditions (as distinct from the primary specification whose unit of observation is a given state-year cell), (3) use mortality rates as the dependent variable that are not risk adjusted for fluctuations in the state-year incidence of the underlying medical conditions, but instead include as covariates the incidence of such conditions, and (4) focus the analysis only on the adult population. For instance, when including the incidence of the underlying medical conditions as covariates (rather than risk adjusting mortality rates ahead of time for such conditions), we estimate a 95 percent confidence band for the noneconomic damage cap coefficient becomes [-0.095, 0.024] as compared with [-0.099, 0.022] from Column 3 of Table 4. For the purposes of brevity, we avoid setting forth this full set of findings. However, these results are available upon request from the authors.

Note that the unit of observation in the inpatient mortality rate specification estimated in the text is a given state-year cell. In an alternative approach (not shown), we estimate linear probability models where the unit of observation is an individual discharge within the sample of inpatient admissions associated with the selected conditions (e.g., acute myocardial infarctions, strokes, etc.) and where the dependent variable is an indicator for inpatient mortality (in such models, we include controls for the incidence of the relevant conditions). The results from this alternative approach are (perhaps not surprisingly) nearly identical to those of the state-year specifications estimated in Table 4 in the text.

Cancer Screening / Damage-Cap Results. The cancer screening results presented in Table 8 of the text are robust to a number of alternative formulations of the relevant cancer screening measures, including alternative formulations of the age restrictions (e.g., those 40 - 75 years old in the case of proctoscopic examination, instead of 50 - 75) and alternative framing of the frequency of the screening - that is, using all of the frequency formulations provided by the BRFSS (e.g., annual, every 2 years, every 5 years, etc.). In the interests of brevity, we do not present the full extent of these alternative formulations, though they are available upon request from the authors. We do, however, present in the following table results (analogous to those from Table 8 in the text) using the incidence of ever having had the relevant screening test as the operable dependent variable. 
Table C5. Relationship between Remedy-Centric Tort Reforms and Cancer Screening Rates. Alternative Formulation:

Incidence of Ever Having the Indicated Screening

\begin{tabular}{|c|c|c|c|c|c|c|}
\hline & (1) & $(2)$ & (3) & (4) & (5) & (6) \\
\hline & $\begin{array}{l}\text { MAMMO- } \\
\text { GRAM }\end{array}$ & $\begin{array}{l}\text { PHYSICAL } \\
\text { BREAST } \\
\text { EXAM }\end{array}$ & $\begin{array}{l}\text { PROCTO- } \\
\text { SCOPIC } \\
\text { EXAM }\end{array}$ & $\begin{array}{c}\text { PSA } \\
\text { TESTING }\end{array}$ & $\begin{array}{l}\text { DIGITAL } \\
\text { RECTAL } \\
\text { EXAM }\end{array}$ & $\begin{array}{c}\text { PAP } \\
\text { SMEAR }\end{array}$ \\
\hline Non-Economic Damage Cap & $\begin{array}{l}0.008^{*} \\
(0.005) \\
\end{array}$ & $\begin{array}{c}-0.000 \\
(0.003) \\
\end{array}$ & $\begin{array}{c}-0.004 \\
(0.007) \\
\end{array}$ & $\begin{array}{c}-0.004 \\
(0.005) \\
\end{array}$ & $\begin{array}{c}0.008 \\
(0.008) \\
\end{array}$ & $\begin{array}{c}-0.002 \\
(0.002) \\
\end{array}$ \\
\hline $\begin{array}{l}\text { 95\% Confidence Band for } \\
\text { Coefficient of Non- } \\
\text { Economic Damage Cap } \\
\text { Variable }\end{array}$ & $\begin{array}{c}{[-0.001,} \\
0.019]\end{array}$ & $\begin{array}{c}{[-0.006,} \\
0.006]\end{array}$ & $\begin{array}{c}{[-0.018} \\
0.010]\end{array}$ & $\begin{array}{c}{[-0.015} \\
0.007]\end{array}$ & $\begin{array}{c}{[-0.009} \\
0.025]\end{array}$ & $\begin{array}{c}{[-0.007,} \\
0.002]\end{array}$ \\
\hline $\begin{array}{l}\text { 95\% Confidence Band, } \\
\text { scaled by mean screening } \\
\text { rate }\end{array}$ & $\begin{array}{c}{[-0.001,} \\
0.026]\end{array}$ & $\begin{array}{c}{[-0.010,} \\
0.010]\end{array}$ & $\begin{array}{c}{[-0.045} \\
0.025]\end{array}$ & $\begin{array}{c}{[-0.028} \\
0.013]\end{array}$ & $\begin{array}{c}{[-0.018} \\
0.050]\end{array}$ & $\begin{array}{c}{[-0.011,} \\
0.004]\end{array}$ \\
\hline $\mathrm{N}$ & 1010415 & 1156433 & 849445 & 252313 & 341102 & 1664055 \\
\hline
\end{tabular}

Notes: robust standard errors corrected for within-state correlation in the error term are reported in parentheses. All regressions included state and year fixed effects.

Source: 1987 - 2008 Behavioral Risk Factor Surveillance System Records.

*** Significant at the 1 percent level.

** Significant at the 5 percent level.

* Significant at the 10 percent level.

Table 8 in the text presents results from the basic difference-in-difference specification without the various control variables included. Table $\mathrm{C} 2$ above, which includes a full set of leads and lags of the damage-cap variable, presents results from specifications that include a range of covariates (as set forth in Online Appendix B above) along with a set of state-specific linear time trends.

Randomization Inference. Following Frakes (2013), we also endeavored to take an alternative route towards estimating the standard errors associated with our estimates. Accordingly, using the sample of observations from our control states, we simulate a set of placebo laws that match the distribution of timing of actual reforms. We then estimate the association between the relevant quality indicator and the placebo laws, replicating this process 5,000 times. We then observe where the actual coefficient from our primary specifications falls in the distribution of coefficients generated through these simulations. Due to time limitations on our use with the data at the NCHS's Research Data Center, we have only performed this exercise on the liability standards analysis for the inpatient mortality rate for selected medical conditions. In the text, we demonstrate that such mortality rates fall by 7.6 percentrepresenting an improvement in quality-upon a national standard adoption in those treatments states that begin the sample with above-average inpatient mortality rates-i.e., in those states with initially lower-than-average quality. While we find that this estimate is statistically significant at the 5 percent level in the main text, we find that this estimate is only significant at the 10 percent level through this randomization inference approach (the estimated -7.6 coefficient falls within the bottom $4.5^{\text {th }}$ percentile of this simulated distribution). 


\section{Tort-Law Generally Damage Caps}

Damage-cap adoptions in many states applied to tort cases broadly, not simply those pertaining to medical malpractice. Damage-cap adoptions in other states applied only to medical malpractice situations. General tort-law caps are arguably likely to pose fewer legislative endogeneity concerns. As such, in other specifications, we replicate the damage-cap analysis by codifying caps using only those adoptions that apply to tort laws more broadly, dropping those states from the analysis that adopted caps in malpractice-specific contexts. If anything, the results of this alternative analysis suggest an even more modest decrease in health care quality connected with damage cap adoptions. For instance, in the case of avoidable hospitalization rates, the coefficient of this modified damage-cap variable is -0.03 , with a 95 percent confidence interval of $[-0.08,0.02]$. In the case of inpatient mortality rates for selected medical conditions, the coefficient is -0.04 , with a 95 percent confidence interval of $[-0.11,0.04]$. The full set of results for this alternative approach are available upon request.

\section{Cancer Screening Liability Standards Analysis.}

As stated in the text, data is available for cancer screening rates over a period of time in which only 3 states modified their standard of care rules: Delaware, Indiana, and Rhode Island. Moreover, only with respect to mammography and pap testing is data available over the full BRFSS period, facilitating any ability to draw upon the experiences of these three treatment states and to properly test for pre-period trends. A further difficulty comes with the fact that even fewer treatment states are available to test the main hypothesis of interest-i.e., that quality will rise in connection with national standard adoptions among those states that begin the sample period with initially low-levels of quality. With respect to mammography, only Indiana is available as a treatment state by which to test this hypothesis. With respect to pap testing, both Indiana and Rhode Island are available for such purposes. While the results of this exercise are arguably unreliable with such few treatment states, we nonetheless present results estimating the relationship between national standard adoptions and the incidence of mammogram screening and pap testing in those states that began with lower than average screening rates and thus with respect to which national standard adoptions arguably represent a heightening of expectations. ${ }^{14}$ In Table C6, we demonstrate how these findings are impacted by (1) the inclusion of the relevant set of covariates discussed in Online Appendix B, (2) the inclusion of state-specific linear time trends and (3) the inclusion of a set of leads and lags of the national standard variable. Note that the analysis below only includes 3 lead periods considering that there are not enough years between the beginning of the sample and Indiana's essential reform to facilitate the estimation of a 4-year lead period.

\footnotetext{
${ }^{14}$ We focus here on estimating the impact of heightened liability standards as opposed to diminished standards. Estimation of this latter type of variation in the law is also compromised by such few treatment groups. Nonetheless, results of this alternative exercise are available upon request. If anything, the results actually suggest that screening rates also increase slightly upon national standard adoptions in those 1-2 states that adopt such reforms when they arguably entail a slackening of standards.
} 
The findings weakly demonstrate that when liability standards change so as to arguably require a heightening of standards, cancer screening rates increase. In the case of mammography screening, rates generally increase subsequent to the reform, strongest with a long lag. However, mammography screening also spiked strongly with a 2-year lead creating some concerns that the increase in quality may reflect a trend that pre-dated the reform. Of course, 1-year lead coefficient does not support any such trend. Pap testing likewise suggests an increase in screening rates with a long lag, while also raising a concern of a pre-period trend, with a strong increase in rates occurring in the year prior to the reform. While this may in part be a reflection of an anticipation effect (Malani and Reif 2012), it may also be reflective of some external factor that correlates (perhaps spuriously) with the increase in screening and with the adoption of the liability reform. 
TABLE C6. The Relationship between National-Standard Laws and the Incidence of Cancer Screening

\begin{tabular}{|c|c|c|c|c|c|c|}
\hline & (1) & (2) & (3) & (4) & (5) & (6) \\
\hline & \multicolumn{3}{|c|}{ MAMMOGRAM SCREENING } & \multicolumn{3}{|c|}{ PAPSMEAR SCREENING } \\
\hline \multicolumn{7}{|l|}{$\underline{\text { National Standard Law }}$} \\
\hline 3-Year Lead Dummy & - & $\begin{array}{c}0.012^{* *} \\
(0.005)\end{array}$ & $\begin{array}{l}0.014 * \\
(0.007)\end{array}$ & - & $\begin{array}{c}0.038 \\
(0.029)\end{array}$ & $\begin{array}{c}0.010 \\
(0.012)\end{array}$ \\
\hline 2-Year Lead Dummy & - & $\begin{array}{c}0.046^{* * *} \\
(0.005)\end{array}$ & $\begin{array}{c}0.048 * * * \\
(0.006)\end{array}$ & - & $\begin{array}{l}-0.017 \\
(0.014)\end{array}$ & $\begin{array}{l}-0.014 \\
(0.015)\end{array}$ \\
\hline 1-Year Lead Dummy & - & $\begin{array}{l}-0.020^{*} \\
(0.011)\end{array}$ & $\begin{array}{l}-0.000 \\
(0.009)\end{array}$ & - & $\begin{array}{l}0.029 * \\
(0.015)\end{array}$ & $\begin{array}{l}0.023^{*} \\
(0.012)\end{array}$ \\
\hline Contemporaneous & $0.040^{* * *}$ & .0140944 & -0.001 & 0.045 & -0.007 & 0.005 \\
\hline Dummy & $(0.006)$ & .0102652 & $(0.009)$ & $(0.033)$ & $(0.020)$ & $(0.027)$ \\
\hline 1-Year Lag Dummy & - & $\begin{array}{l}-0.003 \\
(0.023)\end{array}$ & $\begin{array}{c}0.025^{* *} \\
(0.12)\end{array}$ & - & $\begin{array}{l}-0.003 \\
(0.013)\end{array}$ & $\begin{array}{c}0.013 \\
(0.013)\end{array}$ \\
\hline 2-Year Lag Dummy & - & $\begin{array}{c}0.019 \\
(0.018)\end{array}$ & $\begin{array}{c}0.006 \\
(0.014)\end{array}$ & - & $\begin{array}{l}-0.014 \\
(0.011)\end{array}$ & $\begin{array}{l}-0.009 \\
(0.012)\end{array}$ \\
\hline 3-Year Lag Dummy & - & $\begin{array}{l}-0.036 * \\
(0.021)\end{array}$ & $\begin{array}{l}-0.030 \\
(0.023)\end{array}$ & - & $\begin{array}{c}0.004 \\
(0.020)\end{array}$ & $\begin{array}{l}-0.002 \\
(0.021)\end{array}$ \\
\hline 4-Year Lag Dummy & - & $\begin{array}{c}0.030 * * * \\
(0.007)\end{array}$ & $\begin{array}{c}0.025^{* *} \\
(0.012)\end{array}$ & - & $\begin{array}{l}0.022 * \\
(0.011)\end{array}$ & $\begin{array}{c}0.018 \\
(0.014)\end{array}$ \\
\hline $\mathrm{N}$ & 631592 & 520955 & 520955 & 1098595 & 912364 & 912364 \\
\hline Control Variables? & NO & YES & YES & NO & YES & YES \\
\hline $\begin{array}{l}\text { State-Specific Linear } \\
\text { Trends? }\end{array}$ & NO & NO & YES & NO & NO & YES \\
\hline
\end{tabular}

Notes: robust standard errors corrected for within-state correlation in the error term are reported in parentheses. All regressions include state and year fixed effects. The regressions also include a separate dummy variable indicating whether the state has an initially below-average cancer screen rate (coefficient omitted). Cancer screening data is from the BRFSS.

*** Significant at the 1 percent level.

** Significant at the 5 percent level.

* Significant at the 10 percent level. 